\title{
LA MADERA EN ESPAÑA (c. 1850-c. 1950). UN PRIMER ESBOZO *
}

SANTIAGO ZAPATA BLANCO

Universidad de Extremadura

\section{RESUMEN}

La madera ha sido y sigue siendo un material empleado por el hombre en multitud de aplicaciones, pero apenas ha merecido la atención de los historiadores económicos. El artículo quiere mostrar la diversidad de la problemática económica de la madera y la necesidad de que sea objeto de futuras investigaciones. Se analizan los aspectos forestales, industriales y comerciales de la madera en España, entre mediados del siglo Xx y mediados del siglo XX, teniendo en cuenta los cambios que se estaban produciendo en el uso de la madera y en la evolución de los mercados internacionales. Entre las conclusiones, destaca la «maderización» de la producción forestal española, el incremento y difusión de los aserraderos, la complementariedad de la producción nacional con la madera importada, y el descapitalizador autoabastecimiento de los años de la autarquía.

\begin{abstract}
Wood has always been and will continue being a material used bay man in thousands of different ways, but it has barely received the attention it deser-

N. de E.: Fecha de recepción en la Revista de Historia Económica: septiembre, 1999.

Fecha de aprobación por el Consejo de Redacción: diciembre, 2000.

* En este artículo se recogen algunos de los resultados de los proyectos PB93-0451 y PB96-0618, financiados por la DGICYT y la DGES, respectivamente. Y también he contado, en diversos momentos de la investigación, con la ayuda de Manuel Gutiérrez de Diego, Miquel Gutiérrez i Poch, Antonio M. Linares, Enrique Llopis, Vicente Pinilla, Eduardo Rico, Francisco Zarandieta, mis compañeros del Grupo de Estudios de Historia Rural y dos evaluadores de la Revista. Gracias a todos.
\end{abstract}


ves from economic historians. This article aims to show the great variety of economic problems related to wood as well as to illustrate the need to carry out further research on this matter. Forest, industrial and commercial aspects of wood in Spain from mid-xIx to mid-xx century, taking into account the changes produced in wood use and in the evolution of international markets, are analysed. The most important conclusions of the study include the «lumbering» of Spanish forest production, the increase and spread of sawmills, the complementing of national production with imported timber and the self-sufficient descapitalisation of the autharchic years.

«El monte es, sobre todo, fuente de una materia prima para la industria: la madera». Esta frase lapidaria la escribió, en 1967, el Director General de la FAO en el prefacio de un extenso informe, titulado $L a$ madera: tendencias y perspectivas mundiales ${ }^{1}$. El recordatorio de que la madera es el primero y fundamental de los aprovechamientos forestales no quita importancia a los demás esquilmos; simplemente, los pone en su sitio. Y la indicación de que la madera es una materia prima industrial realza el sentido mercantil de ése y de los demás aprovechamientos forestales y, por extensión, del conjunto de los bosques. La vertiente económica es esencial en las relaciones del hombre con el bosque, y la madera es, por norma (con sus excepciones, claro está), el principal y, a veces, el determinante de todos los aprovechamientos estrictamente económicos.

Quizás aquel Director General fuera, todavía, poco sensible a la multifuncionalidad de los espacios forestales y a las economías externas que éstos proporcionan a todo el planeta en forma de utilidades ambientales no pecuniarias y, por eso, pecara de economicista. Puede ser. Pero ese economicismo me parece la expresión de una actitud intelectual honrada y realista y no lo considero incompatible con una concepción económico-ecológica del patrimonio forestal de la humanidad ${ }^{2}$.

Como voy a hacer un análisis económico muy convencional (porque prescindiré de las mencionadas utilidades ambientales no pecuniarias), debo advertir del enfoque sesgado de mi trabajo; pero creo que esta circunstancia afectará poco a los temas que van a considerarse, tanto para entender los problemas relativos a la madera como la evolución del subsector forestal y de las actividades derivadas del mismo.

' FAO (1967), p. xiii.

${ }^{2}$ Me refiero a una concepción semejante a la que, por ejemplo, se propone en Naredo (1987). 
Tres características del artículo merecen una explicación: el período elegido, la atención especial a España y la visión muy general que va a proporcionarse de la historia económica de la madera. El período escogido coincide con la fase de madurez de la primera revolución industrial y con la segunda revolución industrial. El límite inicial impreciso (circa 1850) obedece a que el uso tradicional de la madera no se vio profundamente alterado hasta que, muy avanzado ya el siglo XIX, las industrias siderúrgica y metalúrgica alcanzaron el grado de eficacia y perfección necesario para que el hierro y, más tarde, el acero llegaran a convertirse en materiales sustitutivos o complementarios de la madera en muchas de las aplicaciones de ésta. El límite final, también impreciso, está justificado por el giro que dio la problemática de la madera en los años centrales del siglo $\mathrm{xx}$, con la consolidación de la pasta como materia prima para la fabricación de papel (cuyo consumo se aceleraba) y, sobre todo, con la generalización del uso de los diversos tipos de tableros. La atención especial a España es obvia, pero, dada la escasa relevancia de nuestro país en la economía maderera del mundo, carece de sentido una historia económica de la madera española en exclusiva, por lo cual resulta imprescindible contemplar los problemas españoles dentro de su contexto internacional. Y la tercera característica del artículo es la modestia de su objetivo, puesto que sólo se trata de un primer esbozo, que allane el camino a sucesivas investigaciones. De ahí que prefiriese, antes que el cuadro detallista de una parte de la historia económica de la madera en España, una visión panorámica pintada con brocha gorda, que también será parcial, puesto que asuntos tan importantes como los relativos a los mercados de maderas sólo los tendré en cuenta de forma circunstancial en la argumentación ${ }^{3}$.

$\mathrm{El}$ texto se ha dividido en cinco epígrafes. En el primero se hacen unos comentarios sobre el estado de la cuestión. En el segundo se tratan cuestiones generales, relativas a las propiedades de la madera y a la evolución que ha tenido su empleo en diversas actividades económicas. En los dos epígrafes siguientes se contempla la problemática de la madera desde dos perspectivas distintas, pero dependientes entre sí: como producto forestal y como materia prima para la industria. Y en el epígrafe quinto se recogen las principales conclusiones ${ }^{4}$.

\footnotetext{
${ }^{3}$ Los mercados de maderas son un tema de entidad y complejidad más que suficientes para ser tratado en otro artículo.

${ }^{4}$ La lista de términos madereros es extensa y el significado de los mismos suele ser equívoco. El diccionario de la Real Academia resuelve bastantes dudas al respecto, pero
} 


\section{UN ESTADO DE LA CUESTIÓN RAQUÍTICO}

Hay que buscar y rebuscar para encontrar algún estudio dedicado expresamente a la historia económica de la madera durante los siglos XIX y $\mathrm{XX}^{5}$. Y esta carencia resulta más llamativa aún cuando se la compara con el ingente número de páginas que los investigadores han dedicado a otras materias primas, como los minerales y metales (y, en particular, el hierro) $\mathrm{e}$, incluso, a otros productos forestales, como el corcho, la resina o el mismo esparto.

En la bibliografía extranjera, dos obras destacan, por su rareza y calidad, sobre las demás. La primera es el libro de Latham, que, pese a haber transcurrido más de cuarenta años desde su publicación, todavía sigue siendo el único manual existente que proporciona una visión histórica general sobre los problemas de la madera en diferentes épocas y países, aunque a través del prisma del comercio exterior británico ${ }^{6}$. Y la segunda es el libro de Rubner, otro manual, dedicado en este caso a la historia forestal europea desde la prehistoria al siglo $\mathrm{xX}$, en el que se presta especial atención al siglo XIX e, indirectamente, a los asuntos relativos a la madera ${ }^{7}$.

El resto de publicaciones, que, con cierta flexibilidad de criterio, podrian tomarse como aportaciones específicas a la historia económica de la madera, suman una veintena de citas, en su mayoría artículos de revistas o contribuciones a libros de varios autores ${ }^{8}$. Casi todas ellas (a diferencia de los textos generales de Latham y Rubner) se refieren a un tema y a un país $\mathrm{y}$, sin forzar mucho las cosas, pueden agruparse por las cuestiones que tratan.

Así, para la época precapitalista se dispone de las actas de una de las «semanas de Prato», donde pueden encontrarse varias ponencias madereras ${ }^{9}$. Asimismo, y pese a su contenido plenamente etnográfico, puede

con frecuencia es preciso acudir a algunas publicaciones especializadas, como Robertson (ed.) (s. a.) o Neira y Martínez (1973).

'He consultado los siguientes repertorios bibliográficos: Martín-Montalvo (1985a), Martín-Montalvo (1985b), Sánchez y Gallego (1993), Tree... (1995), Manuel (1997).

' Latham (1957). Esta obra es de consulta obligada para el investigador, mas no por eso debe dejarse de criticar la excesiva acumulación de noticias, cualitativas y cuantitativas, que se ofrecen al lector sin valorar ni jerarquizar la importancia de cada una de ellas.

7 Rubner (1967). El manual de Hasel (1985) apenas se ocupa de los problemas económicos de la madera. Y el libro de Perlin (1999) es una miscelánea de cuestiones madereras, anteriores casi todas ellas al siglo XIX.

* Sólo estoy teniendo en cuenta el período que ahora me interesa para esta investigación: más o menos, desde mediados del siglo xvir hasta mediados del siglo $\mathrm{xx}$.

${ }^{9}$ Ahvenainen (1996), Collins (1996), North (1996), Woronoff (1996). 
servir al historiador económico el libro de Noël y Bocquet ${ }^{10}$. Un segundo grupo estaría compuesto por las investigaciones dedicadas a las industrias derivadas de la madera, especialmente a las que suelen denominarse de «primera transformación», las que más me interesan ahora, dada su estrecha vinculación con los aprovechamientos forestales ${ }^{11}$. Estarian aquí los trabajos dedicados al aserrío y a las cuestiones técnicas relacionadas con el mismo ${ }^{12}$; tres libros, donde se hace especial mención a la madera de construcción y a la destinada a traviesas del ferrocarril ${ }^{13}$; y un artículo sobre la madera en la industria francesa de la costrucción naval ${ }^{14}$. Y el tercer grupo estaría formado por los trabajos que se han ocupado de la comercialización de la madera, con los cuales cabe hacer dos subgrupos. Uno, con aquellos que tratan temas relativos al comercio exterior ${ }^{15}$; y un segundo subgrupo, donde están las investigaciones que se han atrevido con el intrincado asunto de los precios de la madera y ofrecen series y procedimientos de análisis de esta importantísima variable ${ }^{16}$.

Una escasa cosecha, pero que resulta abundante cuando se la compara con la bibliografía análoga disponible para el caso español, ya que no existe ni una sola investigación que trate de forma directa y monográfica sobre la historia económica de la madera en España durante los siglos XIX y $\mathrm{xx}$. Sin embargo, existen unas pocas publicaciones donde se trata (casi siempre, de pasada) de la problemática de la madera y es obligado mencionarlas. Los dos trabajos más monográficos que pueden citarse: un libro

${ }^{10}$ Noël y Bocquet (1987).

11 Por este motivo, prescindo de la industria papelera moderna, basada en la pasta de madera, que tal vez sea la industria derivada de la madera que más ha atraído la atención de los investigadores. Sobre las actividades que pueden considerarse de «primera transformación», no existe una opinión unánime, aunque el aserrado es, sin duda, la principal de todas ellas. Sin embargo, hoy día, cabe considerar también de primera transformación al desenrollo y a la trituración, por la general importancia que han adquirido los tableros en sus diversas formas en las últimas décadas [Vignote y Jiménez (1996), pp. 311-312].

${ }_{12}$ Killian (1982), Ahvenainen (1985), Agnoletti (1995), Agnoletti (1996), Agnoletti (1998), Agnoletti (1999), que ofrece una panorámica de los problemas económicos de la madera en Italia durante el último tercio del siglo xxx y el primero del xx. El libro de Ahvenainen (1984) no he podido leerlo, por estar escrito en finés.

${ }^{13}$ Steer (ed.) (1948), Turner (1990), Chew (1992).

${ }^{14}$ Chabrol (1962).

15 Soederlund (ed.) (1952), Fitzgerald y Grenier (1992), Cox (1988), Laarman (1988), Ahvenainen (1988a), Ahvenainen (1988b), Björklund (2000).

16 Eggert (1883), Rubner (1920), Chapon (1961), Guillard y Rossner (1974), Buttoud (1977), Perrot (1957a), Perrot (1957b), Soulères (1997a), Soulères (1997b). En Rubner (1920), p. 13, se dice: «en situación de libre competencia, los precios de la madera dominan toda la economía forestal; de ellos depende, como suele decirse, lo bueno y lo malo de nuestros montes». 
y un artículo de Aranda, sobre la participación de la madera en la construcción naval del siglo XviI ${ }^{17}$. Tres textos del Grupo de Estudios de Historia Rural, y uno de Zambrana, en los cuales se alude a la «maderización» de la producción forestal ${ }^{18}$. Algunas páginas de los estudios que Pinilla, Sabio y Araque han realizado, respectivamente, sobre los montes públicos de Aragón, Huesca y Jaén ${ }^{19}$. Un epígrafe de un capítulo de uno de los libros de Gómez Mendoza, en el que se comentan los efectos de las construcciones ferroviarias sobre la industria maderera ${ }^{20}$. Diversas partes de las tesis doctorales de Espido, Sala y Rico, así como una obra reciente de este último ${ }^{21}$. El conocido libro de Paris, porque proporciona series de precios de madera y de otros materiales de construcción, tan difíciles de encontrar ${ }^{22}$. Y dos capítulos (el 5 y, sobre todo, el 6) de la tesis doctoral de Iriarte, en los que, junto a unos cuantos pasajes madereros, se trata del funcionamiento de los mercados de productos forestales (la madera incluida, claro está) ${ }^{23}$.

En resumen, un estado de la cuestión bastante raquítico, aunque, en esta situación de penuria, todos los trabajos citados prestan una inestimable ayuda al investigador que se asoma por primera vez a los temas madereros. En consecuencia, y atendiendo a los objetivos de la presente investigación, concentré mis pesquisas en algunas fuentes y desestimé otras, por las razones que, de forma muy sucinta, expongo a continuación.

Las fuentes de época utilizadas (aparte de una docena de libros) han sido revistas especializadas y estadísticas. Un ejercicio de cata en estas revistas desveló el elevado rendimiento que podía obtenerse de la consulta sistemática de una serie de títulos que apenas habían mirado los historiadores económicos ${ }^{24}$.

17 Aranda (1991), Aranda (1995).

18 (En esta nota y en lo sucesivo, me referiré al Grupo de Estudios de Historia Rural con la abreviatura GEHR). GEHR (1996a), GEHR (1996b), GEHR (1996c), Zambrana (1998).

${ }^{19}$ Pinilla (1995b), pp. 427.439; Sabio (1997), pp. 57.77; Araque (1997), pp. 113.127 y 237-249.

20) Gómez Mendoza (1989), pp. 106-116.

${ }^{21}$ Espido (1995), t. I, pp. 308-334, y t. II, pp. 237-255; Sala (1998), pp. 319-402; Rico (1994), pp. 159-177; Rico (1999).

${ }^{22}$ Paris (1943).

${ }^{23}$ Iriarte (1995). Los dos capítulos mencionados son la parte de la citada tesis doctoral que no se publicó en Iriarte (1997).

${ }^{24}$ En la Hemeroteca de la Escuela Técnica Superior de Ingenieros de Montes, de Madrid, se encuentran la mayor parte de las revistas consultadas. Esta Hemeroteca y la Biblioteca de la misma Escuela, con siglo y medio de existencia, son los mejores centros 
La diferente importancia de las revistas consultadas obedece al número de años de la colección, pero en mayor medida a otros factores, que sería prolijo detallar aquí ${ }^{25}$. Sólo señalaré las revistas que, por diversos motivos, me han parecido de mayor interés: entre las españolas, Revista de Montes, Revista de Montes y Plantios, España Forestal, La Madera y sus Industrias, Montes e Industrias y Montes; y, entre las extranjeras, Joumal Forestier Suisse (Schweizerische Zeitschrift für Forstwesen), Revue Forestière Française y Unasylva.

E1 segundo tipo de fuentes de la época utilizadas han sido las estadísticas. Pero estadísticas propias de la madera no existen (que yo sepa) y es preciso valerse de repertorios conocidos, por lo que huelgan los comentarios y será suficiente con hacer la lista de los empleados: Estadisticas de la Producción de los Montes de Utilidad Pública (o de los Montes Públicos) ${ }^{26}$; Estadística Forestal de España ${ }^{27}$; Estadisticas del Comercio Exterior de España; Estadística Administrativa de la Contribución Industrial y de Comercio ${ }^{28}$; y Estadística de las Industrias de Primera Transformación de la Madera ${ }^{29}$.

Tres colecciones más deberían figurar en este grupo. La primera sería la formada con las estadísticas forestales que publicó el Instituto Internacional de Agricultura en las décadas de 1920 y 1930 . Me consta su existencia, porque las he visto citadas, pero no he tenido la suerte de que llegaran a mis manos. La segunda, la Estadística del Comercio de Cabotaje y, la tercera, la colección de las denuncias de la Guardia Civil impuestas por los delitos e infracciones cometidos en los montes públicos ${ }^{30}$, pero el empleo de estas dos me parece más apropiado para una etapa posterior

de información de toda España para los interesados en la historia forestal. Lástima que las condiciones de consulta sean tan precarias e incómodas, salvo en los períodos de vacaciones estudiantiles. Por lo que a mí respecta, no obstante, recibí un trato exquisito por parte del personal encargado de atender al público, al que estoy muy agradecido.

${ }^{25}$ En Gómez Mendoza (1992), pp. 9.15, se facilita información sobre varias de las revistas españolas utilizadas.

26 Esta fuente se describe y critica en GEHR (1991), pp. 62-77.

${ }^{27}$ Sólo utilizaré esta colección de forma esporádica. Una crítica de su contenido se ha hecho en GEHR (1996b) y en Zambrana (1998).

${ }^{28}$ En Equipo Investigador (1996), pp. 40-53, se hace una exposición crítica de los contenidos de esta fuente.

${ }^{29}$ Ministerio de Agricultura (1963a); Ministerio de Agricultura (1963b); Ministerio de Agricultura (1964); Dirección General de Montes, Caza y Pesca Fluvial (1964); Dirección General de Montes, Caza y Pesca Fluvial (1965). Esta colección continuó publicándose hasta 1969.

${ }^{30}$ Esta fuente ha sido criticada y utilizada en GEHR (1999). 
de la investigación, cuando el análisis descienda a los niveles de la región o la provincia.

Y tampoco me he servido de una documentación manuscrita, de excepcional riqueza informativa para todas las cuestiones forestales, como son los planes de aprovechamiento forestal, depositados en el Archivo del Ministerio de Agricultura y en el Archivo General de la Administración Pública ${ }^{31}$. $\mathrm{Al}$ igual que en el caso de las denuncias de la Guardia Civil y de las cifras del cabotaje, considero que puede prescindirse de esta voluminosa colección en trabajos de corte muy general, como el que aquí se presenta ${ }^{32}$.

\section{UNA MATERIA PRIMA MUY HETEROGÉNEA CON MULTITUD DE APLICACIONES}

El título del epígrafe se refiere a las dos características de la madera que más influyen en su utilización por parte del hombre. La madera tiene esa propiedad que distingue a los seres animados, que es la diferenciación individual ${ }^{33}$. $Y$, gracias a esta intrínseca heterogeneidad, derivada de su constitución celular, es posible dar a la madera una gran diversidad de empleos ${ }^{34}$.

Pero la heterogeneidad es también un inconveniente, cuando se busca la regularidad de los insumos y de los productos, como sucede desde que los procesos de producción mecánicos se han ido generalizando en todas partes y en todos los sectores con el triunfo de la industrialización, ya que dicha regularidad se consigue más fácilmente con otros materiales, como los metales (y, en particular, con el hierro y el acero), que irán sustituyendo a la madera en muchos de sus empleos tradicionales.

Sin embargo, la misma madera, que se desechaba en ciertas aplicaciones, podía ser la base de una nueva actividad productiva. Tenía razón Nájera, uno de nuestros técnicos que más escribió sobre temas madereros,

${ }^{31}$ Esta fuente se describe y critica en GEHR (1991), pp. 77-78.

${ }^{32}$ No obstante, en Pinilla (1995b), pp. 427-439, y Sabio (1997), pp. 57-77, puede verse lo mucho que da de sí la citada colección en estudios de carácter provincial o regional.

${ }^{33}$ Vignote y Jiménez (1996), p. 211. Y continúan estos autores en la misma página: «Pero no solamente es cierto que cada árbol es distinto del resto, sino que, aun dentro del mismo individuo, las características de la madera varían con la posición en relación al eje y a la altura sobre el suelo.» Las condiciones concretas en que se desarrolla cada árbol modifican, también, los resultados de sus posibles aprovechamientos [Leban, Saint-André y Triboulot (1998)], aunque es cierto que las variaciones dentro de una misma especie suelen ser de poca importancia.

${ }^{34}$ «Se dice que hay más de 4.000 formas distintas de uso» [Brown (1937), p. 3]. 
cuando afirmaba que «no existe en la Naturaleza otra materia prima [como la madera] de la que el hombre haya obtenido tantos beneficios y sacado tantas aplicaciones» ${ }^{35}$.

Los muchos servicios que la madera ha prestado al hombre nacen de sus propiedades, que voy a recordar brevemente. Pero, asimismo, proceden del ingenio humano, que ha sabido valerse de esas propiedades y adaptarlas a diferentes necesidades. $Y$ esto se observa especialmente en aquellos períodos, como el contemplado en este trabajo, en el que tienen lugar transformaciones de toda índole, de modo que, respecto a la madera (presente en cualquier manifestación de la vida cotidiana) cabe hablar de usos declinantes, usos renovados y usos emergentes.

\subsection{Propiedades de la madera}

Las principales propiedades que distinguen a la madera de otros materiales son las siguientes ${ }^{36}$ : baja densidad ${ }^{37}$; anisotropía, a diferencia de los metales, que son isótropos ${ }^{38}$; mucha porosidad, debido al carácter celular de su elementos constitutivos; escasa conductibilidad calorífica y eléctrica; elevada interacción con la humedad ${ }^{39}$; buena resistencia a la oxidación, pero muy poca a organismos vivos xilófagos (insectos, hongos, moluscos); acusada variabilidad en el conjunto de las propiedades físicas, no sólo entre distintas especies, sino, incluso, dentro de la misma especie, según las circunstancias en que haya crecido el árbol del que proceda la madera; y, al contrario de lo que sucede con las propiedades físicas, una composición química análoga para toda clase de maderas, en la que destacan la celulosa (del 40 al 62 por 100 del peso de la madera) y la lignina (del 20 al 30 por 100 de dicho peso).

La natural heterogeneidad de la madera también es el origen de algunos de sus defectos y de especiales cualidades. Los nudos (que acarrean incon-

\footnotetext{
${ }^{35}$ Nájera (1934), p. 5.

36 Nájera (1934), pp. 16-20 y 35; Enciclopedia... (s. a.), t. XXXI, pp. 1305-1311; Nöel y Bocquet (1987), p. 67; Vignote y Jiménez (1996).

${ }_{37}$ La densidad de la madera va de 0,1 a 1,3 , mientras que la de los metales y sus aleaciones está entre 1,8 y 22.

${ }^{38}$ Por eso, en la madera suelen distinguirse la dirección axial (la del eje del árbol), que es la que ofrece una mayor resistencia mecánica, la dirección radial (la de los radios, perpendicular al eje del árbol) y la dirección tangencial (la de la tangente, perpendicular al eje del árbol).

${ }^{39}$ Ello trae consigo variaciones en la dimensión y en las propiedades físicas y mecánicas de la madera, lo cual influye notablemente ( $\mathrm{y}$ de forma negativa, por lo general) en su proceso de elaboración (aserrado, desenrrollo, cepillado, encolado, etc.).
} 
venientes de orden físico, mecánico o estético) son el principal defecto de la madera, hasta el punto de que, en la mayoría de las especies, se convierten en uno de los parámetros más influyentes a la hora de fijar el precio de la pieza en cuestión.

Pero existen otras anomalías que modifican, asimismo, las propiedades de la madera. El Cuadro 1 recoge las exigencias habituales para los destinos

\section{CUADRO 1}

Propiedades físicas exigidas para los distintos destinos de la madera

\begin{tabular}{|c|c|c|c|c|c|c|c|c|c|c|c|}
\hline \multirow{3}{*}{ Destino } & \multicolumn{4}{|c|}{ Dimensiones * } & \multirow[b]{3}{*}{$\begin{array}{c}\text { Curvat. } \\
\text { fuste }\end{array}$} & \multirow[b]{3}{*}{$\begin{array}{l}\text { Conic. } \\
\text { fuste }\end{array}$} & \multirow[b]{3}{*}{ Nudos } & \multirow[b]{3}{*}{$\begin{array}{l}\text { Fendas } \\
\text { o Aceb. }\end{array}$} & \multirow[b]{3}{*}{$\begin{array}{l}\text { Pica- } \\
\text { duras }\end{array}$} & \multirow[b]{3}{*}{$\begin{array}{l}\text { Azu- } \\
\text { lado }\end{array}$} & \multirow[b]{3}{*}{$\begin{array}{l}\text { Pudri } \\
\text { ción }\end{array}$} \\
\hline & \multicolumn{2}{|c|}{ Diámetro } & \multicolumn{2}{|c|}{ Longitud } & & & & & & & \\
\hline & Min. & Máx. & Min. & $\operatorname{Max}$ & & & & & & & \\
\hline Aserrado. & 20 & & 2 & 6 & $\mathrm{E}$ & $E$ & $\mathrm{E}$ & $\mathrm{E}$ & $N$ & $\mathrm{E}$ & $N$ \\
\hline Desenrollo. & 35 & & 1,2 & 2,5 & $\mathrm{ME}$ & $\mathrm{ME}$ & $\mathrm{E}$ & $E$ & $\mathrm{~N}$ & $\mathrm{E}$ & $\mathrm{N}$ \\
\hline Chapa plana .. & 35 & & 1,2 & 2,5 & $\mathrm{~N}$ & $N$ & $N$ & $\mathrm{~N}$ & $\mathrm{~N}$ & $\mathrm{~N}$ & $\mathrm{~N}$ \\
\hline Postes ............... & 20 & 45 & 8 & 16 & $\mathrm{~N}$ & $\mathrm{~N}$ & $\mathrm{E}$ & $\mathrm{E}$ & $\mathrm{N}$ & $\mathrm{E}$ & $\mathrm{N}$ \\
\hline Ademes........... & 7,5 & 15 & 2,5 & & $\mathrm{~N}$ & $\mathrm{~N}$ & $\mathrm{P}$ & $\bar{P}$ & $\mathrm{~N}$ & $\bar{P}$ & $\mathrm{~N}$ \\
\hline Cercas.. & 7,5 & 15 & 2,5 & & $\mathrm{E}$ & $\mathrm{E}$ & $\mathrm{P}$ & $\mathrm{P}$ & $\mathrm{P}$ & $\mathrm{P}$ & $\mathrm{N}$ \\
\hline Tableros......... & 7 & 35 & 1 & 2,5 & I & I & A & I & I & I & $N$ \\
\hline Pasta ............... & 7 & 35 & 1 & 2,5 & I & I & A & I & I & I & I \\
\hline Xiloenergético. & 5 & 35 & & & I & I & I & I & I & I & I \\
\hline
\end{tabular}

* Diámetro en $\mathrm{cm}$ y longitud en $\mathrm{m}$.

LEYENDA: N (ninguno); ME (muy escaso); E (escaso); P (pocos); A (admisible); $I$ (indiferente).

FUENTE: Vignote y Jiménez (1996), p. 74.

más frecuentes de la madera y pone de manifiesto que los inconvenientes para algunas aplicaciones pasan inadvertidos en otras. La curvatura y la conicidad del tronco, las bifurcaciones, el espesor irregular de los anillos, la excentricidad del corazón, el azulado, la madera enteada o las picaduras y pudriciones (debidas a la acción de organismos xilófagos) rebajan la calidad de la madera. En cambio, la madera de corazón, los anillos festonados o la fibra ondulada incrementan (a veces, considerablemente) el valor de la madera para algunas aplicaciones. 


\subsection{Usos declinantes, usos renovados y usos emergentes}

Simplificando mucho, podrían establecerse dos grandes etapas en la evolución del empleo de la madera durante los siglos $\mathrm{XIX}$ y $\mathrm{XX}$, tomando como criterio de separación la relativa utilización que se haya hecho de la madera maciza o de la madera triturada. El criterio es arbitrario (como cualquier otro que se hubiera elegido en su lugar), pero se adapta bien a los objetivos de este trabajo, puesto que la presencia de la madera triturada o desintegrada es, a la vez, causa y efecto de dos importantes cambios en la economía de la madera. El primero actúa en el ámbito de lo forestal, favoreciendo la difusión de las especies más aptas para la trituración (de crecimiento rápido y productoras de madera blanda) en detrimento de las que proporcionan madera maciza (más dura, y que tarda mucho más tiempo en formarse), lo cual influye, asimismo, en los sistemas de explotación ${ }^{40}$. Y el segundo se refiere a profundas variaciones en las técnicas de transformación industrial, pues, mientras que la madera maciza suele aprovecharse con métodos tradicionales, el empleo masivo de la madera triturada (cuyo ejemplo más emblemático es la pasta de papel) sólo puede llevarse a cabo con sofisticados y costosos procedimientos, que requieren cuantiosas inversiones.

De este modo, atendiendo al criterio escogido, se tendría una primera época, que abarcaría el siglo XIX (más o menos), en la que habría prevalecido el uso de la madera maciza, casi de forma exclusiva. Y una segunda época, que comenzaría con el siglo xx (también, más o menos), en la que se ha ido haciendo un empleo cada vez mayor de la madera triturada, hasta llegar a la situación actual, que podría calificarse de claro predominio relativo de dicha madera triturada, por comparación con la posición secundaria que tiene hoy el uso de la madera maciza.

El creciente empleo de la madera triturada ha sido la consecuencia del avance de las nuevas industrias de fabricación de papel y de tableros.

41) La siguiente cita se refiere a los montes públicos, pero puede aplicarse a todos los terrenos forestales: «En términos generales, los cambios que se fueron dando en las industrias relacionadas con la actividad forestal fueron determinantes para que los ingenieros de montes $\multimap$, al menos, algunos de ellos- se replantearan [...] el problema del turno de explotación y de la cortabilidad, ya que mientras las actividades tradicionales, que estaban decayendo, necesitaban maderas de grandes dimensiones, las que estaban alcanzando posiciones punteras no requerían piezas grandes, sino que se podían desarrollar con árboles de dimensiones más modestas [...] o incluso llevarse a cabo con un alto grado de independencia respecto al tamaño de los árboles. Éste era el caso de la celulosa, para cuya obtención eran más importantes las características físicas de la madera [...] que sus dimensiones. Y era también el caso, aún en mayor medida, de las industrias de destilación» [Iriarte (1995), pp. 609-610]. 
La moderna industria papelera dio sus primeros pasos a finales del siglo XIx y experimentó una rápida expansión en los países desarrollados, al tiempo que sus métodos se iban transformando y haciendo más complejos con la ayuda de la industria quimica ${ }^{41}$. Sin embargo, la fabricación de tableros (a la que dedicaré unos párrafos más abajo) no tuvo entidad apreciable hasta bien entrado el siglo $\mathrm{xx}$, ya que sólo después de la segunda guerra mundial ( $y$, por lo tanto, al término del período al que se refiere este artículo) empezó a difundirse el uso de los tableros de partículas y de fibras. De forma que es en la segunda mitad del siglo xx cuando se han sumado los efectos de la industria papelera y de la de tableros, y cuando la madera triturada ha ido ascendiendo hasta la posición dominante que tiene en la actualidad.

En el transcurso de las dos épocas mencionadas se distinguen notables modificaciones, que rompen con el relativo inmovilismo de siglos anteriores y ponen de manifiesto la amplia gama de aplicaciones de que es susceptible la madera. Así, se produce una mezcolanza de situaciones, en la que coexisten los usos declinantes de la madera con otros antiguos, que van renovándose, y con otros, completamente nuevos, que emergen y van expandiéndose con rapidez, como queda reflejado en el Cuadro 2, cuya misión es la de aligerar y hacer más comprensibles los siguientes comentarios.

Tal vez, el más característico de los usos declinantes haya sido el relativo a la construcción naval, donde la madera fue sustituida casi por completo, primero, por el hierro, y luego, por el acero, en un proceso que duró todo el siglo $\mathrm{XIX}^{42}$. Un barco de hierro no sólo era más seguro y navegaba a más velocidad que otro de madera; también podía ser mucho más largo $y$, por consiguiente, tener una capacidad mucho mayor ${ }^{43}$.

Entre finales del siglo xvm y principios del XIX, Gran Bretaña ya disponía de conocimientos científicos y capacidad técnica para fabricar barcos de hierro. Sin embargo, la sustitución de la madera por el hierro (y, más tarde, por el acero) fue lenta, pues no se generalizó hasta la segunda mitad (o el último tercio) del siglo XIX. Entre las razones de este paulatino progreso, estaba el mucho sitio que debía reservarse al carbón en el barco de vapor, con la consiguiente merma del espacio para pasajeros y mer-

${ }^{41}$ No me ocuparé en este trabajo de la industria papelera española ni de su entorno mundial, porque está siendo investigada, con gran acierto, por Gutiérrez i Poch. A sus publicaciones me remito: Gutiérrez (1994), Gutiérrez (1996).

${ }^{42}$ Derry y Williams (1977), pp. 537.548.

${ }^{43}$ La máxima eslora en un barco de madera no podía pasar de 90 metros, debido a las limitaciones físicas impuestas por la resistencia de la madera [Derry y Williams (1977), p. 539]. 


\section{CUADRO 2}

Cambios en el empleo de la madera en los países desarrollados, durante los siglos XIX $y \mathrm{XX}$

\begin{tabular}{|c|c|}
\hline & Empleo \\
\hline \multicolumn{2}{|l|}{ Usos declinantes } \\
\hline 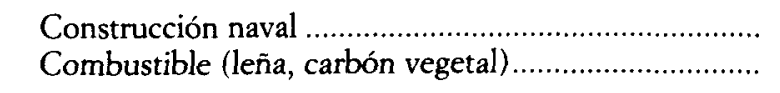 & $\downarrow \downarrow \downarrow$ \\
\hline \multicolumn{2}{|l|}{ Usos renovados } \\
\hline 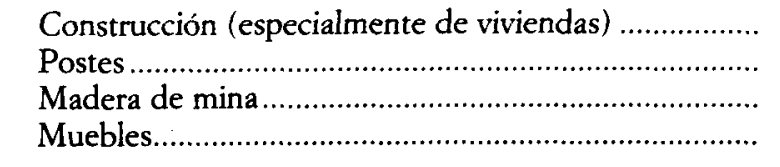 & $\begin{array}{c}\downarrow \\
\uparrow \uparrow \\
\uparrow \uparrow \\
\downarrow\end{array}$ \\
\hline \multicolumn{2}{|l|}{ Usos emergentes } \\
\hline  & $\begin{array}{l}\uparrow \uparrow \\
\uparrow \uparrow \uparrow \\
\uparrow \uparrow \uparrow \\
\uparrow \uparrow \uparrow \\
\uparrow \uparrow \uparrow \\
\end{array}$ \\
\hline $\begin{array}{rll}\text { LEYENDA: } & \downarrow & \text { (disminución en términos relativos, pero } \mathrm{n} \\
& \downarrow \downarrow \text { (disminución en términos relativos y absolut } \\
& \downarrow \downarrow \downarrow \text { (empleo que desaparece casi por completo) } \\
& \uparrow \quad \text { (aumento en términos relativos, pero no abs } \\
& \uparrow \uparrow \text { (aumento en términos relativos y absolutos) } \\
& \uparrow \uparrow \uparrow \text { (empleo que aumenta con mucha rapidez). }\end{array}$ & $\begin{array}{l}\text { absolutos) } \\
\text { s). } \\
\text { lutos). }\end{array}$ \\
\hline
\end{tabular}

cancías, de suerte que la construcción de los barcos de hierro se retrasó hasta que hubo suficientes puertos aprovisionadores de carbón.

El abandono de la madera en la construcción naval recibió un impulso definitivo con la sustitución del hierro por el acero en el último cuarto del siglo XIX. El acero se trabajaba con más facilidad que el hierro y los barcos de acero tenían un peso menor que los de hierro, lo cual permitía un incremento de la velocidad, un ahorro de combustible y mayor facilidad para adaptar el espacio de los barcos a las nuevas necesidades, procedentes de la especialización de la marina mercante, que comenzó a finales del siglo $\mathrm{xx}^{44}$.

${ }^{44}$ Estas transformaciones trajeron consigo importantes cambios en la localización de la industria de la construcción naval. Hasta mediados del siglo xIx, cuando predominaban los barcos de madera, la mitad de la construcción naval se realizaba en el litoral americano 
Otro uso declinante ha sido el empleo de la madera como combustible en forma de leña y carbón vegetal. Pero esta afirmación sólo es válida para los países desarrollados, ya que todavía hoy se destina a la producción de energía más de la mitad de la madera producida en todo el mundo, si bien esta proporción es de un 18 por 100 en los citados países desarrollados y se acerca al 80 por 100 en los más atrasados ${ }^{45}$. La urbanización progresiva, así como la mayor disponibilidad de combustibles fósiles a bajo precio (desde el carbón mineral al gas natural, pasando por el petróleo y sus derivados) han restringido la utilización de la leña a los países subdesarrollados y a las zonas más rurales y aisladas de las naciones industriales. Pero dicha utilización ha tenido y aún tiene una elevada dosis de autoconsumo, de manera que, a pesar de tratarse de producciones con idéntico origen, a la hora del análisis económico es necesario distinguir, por un lado, la madera, propiamente dicha, como materia prima que se destina al mercado para que sea transformada por la industria antes de su consumo por el hombre, y, por otro, la leña, como un producto muy poco mercantilizado, que, con frecuencia, es recolectado por el propio consumidor que va a servirse del mismo.

Dentro de los usos renovados, según la clasificación del Cuadro 2, estaría el empleo de la madera en la construcción en general y, en particular, de viviendas. Empleo antiquísimo (como el de la construcción naval), que fue perdiendo importancia relativa desde principios del siglo $\mathrm{Xx}$, mientras la ganaban los metales y, en particular, el hierro y el acero ${ }^{46}$.

Dos circunstancias contribuyeron a la búsqueda de materiales alternativos a la madera en la construcción. El primero, y más importante, fueron los incendios; y, el segundo, la demanda de grandes edificios, de características inusuales hasta entonces (como fábricas, almacenes, mercados cubiertos, estaciones ferroviarias, etc.), para atender necesidades emanadas de las nuevas circunstancias económicas y sociales en que se desenvolvía la industrialización.

El hierro y el acero, además de ofrecer más resistencia que la madera al fuego y a los seísmos, presentan la ventaja de adaptarse mejor al desarrollo

y canadiense, «donde los precios de la madera hacían imposible la competencia británica» [Derry y Williams (1977), p. 538]. Sin embargo, a finales de siglo, el hierro y el acero trasladaron la hegemonía de la construcción naval a Gran Bretaña, de donde procedía el 80 por 100 del tonelaje de la flota mercante del mundo.

45 Vignote y Jiménez (1996), p. 22.

4h Campo (1888); Latham (1957), pp. 258-264; Derry y Williams (1977), pp. 588-598 y 601-609; Seitz (1998); Triboulot y Leban (1998). 
de técnicas de producción masiva. Tienen el inconveniente, sin embargo, de su mayor facilidad para la corrosión. En una magnitud imposible de precisar, la madera fue sustituida por el hierro y, sobre todo, por el acero, desde el último tercio del siglo xx. Poco después, se pondría a punto la utilización del cemento Portland, y esto también aminoró el empleo de la madera en la construcción.

Ahora bien, el caso de la construcción de viviendas es muy distinto al de la construcción naval. En éste, la madera sólo continuó utilizándose en proporciones ínfimas. En las viviendas, por el contrario, el empleo de la madera decayó en términos relativos, pero (con seguridad, aunque sea una seguridad meramente intuitiva, por falta de datos) no en términos absolutos, dado el rápido crecimiento de la población mundial, de la urbanización y de la renta disponible (especialmente, en los países desarrollados) durante el siglo XIX y la primera mitad del siglo Xx. De hecho, hacia 1950, al final del período contemplado en este trabajo, la construcción de viviendas debía de ser aún el principal destino de la madera ${ }^{47}$. Pero no es menos cierto que la cantidad de madera empleada en estos menesteres sería reducida con respecto a los demás materiales de construcción ${ }^{48}$. Y menos mal, puesto que habría sido imposible que los bosques del planeta surtieran

${ }^{47}$ Sobre este particular, en FAO (1967), pp. 12.13, se hacen unas precisiones que vale la pena transcribir: «El aprovechamiento efectivo de la madera aserrada en el marco de un sector concreto tiende a presentar variaciones muy amplias de una zona a otra. Tomando como ejemplo el ramo de la vivienda, de por sí el mayor uso final de la madera aserrada en casi todas partes, se ve que en los Estados Unidos se utiliza un promedio de $20,5 \mathrm{~m}^{3}$ de madera aserrada por cada nueva vivienda; en Europa noroccidental, la cifra es de 6,8 $\mathrm{m}^{3}$; en los paises mediterráneos de Europa, de 3,7 $\mathrm{m}^{3}$; y en el sur de Asia se emplea menos de $1 \mathrm{~m}^{3}$ [...] Naturalmente, existen grandes diferencias en cuanto al tamaño de las viviendas, pero también la madera aserrada se utiliza de formas muy diversas dentro del sector de la construcción en las diferentes regiones. En Estados Unidos, la madera aserrada es el principal material estructural para el armazón de edificios y armaduras de cubiertas y superficies de asiento de pisos; se emplea también para revestimiento de paredes, suelos,... [...] En Europa noroccidental, la madera aserrada no se utiliza prácticamente nunca para la estructura o revestimiento de paredes, se emplea rara vez para asiento de pisos y sólo tiene un aprovechamiento limitado para armadura de cubiertas; se usa para carpintería de taller, acabados, accesorios y encofrado. En el sur de Europa, la madera aserrada se emplea poco más que para carpintería de taller, acabados y accesorios. En el sur de Asia se utiliza sólo para carpintería de taller.m

${ }^{4 *}$ Los datos que siguen proceden de Triboulot y Leban (1998), p. 18. Aunque los autores no lo indican, supongo que se refieren a la situación actual de Francia, donde la mayor parte de la madera aserrada (el 58 por 100) se destina a la construcción, pero donde esta madera sólo representa el 8 por 100 de todos los materiales de construcción, al lado del 35 por 100 de las materias minerales, del 32 por 100 de los materiales metálicos y del 25 por 100 de los petroquímicos. 
de madera de construcción a una población con crecimiento exponencial y con niveles de vida en continuo aumento.

De este modo, los usos de la madera de construcción fueron renovándose $\mathrm{y}$ adaptándose a un contexto muy diferente del que tuvieron en el pasado. $\mathrm{Y}$ algo parecido cabe decir de otros empleos de la madera, que también venían de antiguo, pero que, en este caso, se vieron incrementados por nuevas actividades económicas propias de la industrialización, como sucedió, por ejemplo, con la madera de mina, o con los postes, que, a sus muchos empleos anteriores, añadieron ahora el de sostén de las líneas telefónicas y eléctricas.

La fabricación de muebles puede considerarse, asimismo, otro de los usos renovados de la madera, gracias a la mecanización de la carpintería y al estímulo, repetidamente mencionado, de una población urbana creciente y con un mayor poder adquisitivo, aunque también aquí el hierro sustituyó con ventaja a la madera, especialmente en las camas, la parte más indispensable del mobiliario familiar ${ }^{49}$.

El último grupo, que he denominado de usos emergentes, tiene, pese a su diversidad, el común denominador de ser completamente nuevo con relación a los empleos tradicionales de la madera. El más simple de todos ellos es el de las traviesas para el ferrocarril, que absorbió, en los momentos álgidos de la fiebre ferroviaria, una porción considerable de madera, que luego fue reduciéndose, a medida que se completaban las redes, que se generalizaban los métodos de impregnación de la madera y que, finalmente (en la segunda mitad del siglo $\mathrm{xx}$ ), se han ido sustituyendo las traviesas de madera por las fabricadas con otros materiales, como el hormigón.

Sin embargo, los usos emergentes por excelencia son los comprendidos en los capítulos de la pasta de madera y de los tableros. La producción de pasta es una rama de la industria química moderna de la que se obtienen una gran variedad de artículos, entre los que destacan los derivados de la celulosa, y que tuvo, en el período que aquí se estudia, como principal aplicación la fabricación de papel ${ }^{50}$. En los últimos años del siglo XIX y en las primeras décadas del siglo $\mathrm{xx}$, la pasta de madera fue sustituyendo a las anteriores materias primas empleadas en la fabricación del papel,

${ }^{49}$ Derry y Williams (1977), pp. 598-601. Los autores recuerdan que, desde la revolución francesa, la cantidad y calidad de los muebles eran considerados un distintivo del nivel social del hogar donde se encontraran. Y, asimismo, se refieren a la progresiva utilización, desde finales del siglo xx, del tablero contrachapado, en lugar de la madera maciza, para la fabricación de muebles.

${ }^{50}$ Además de los derivados de la celulosa, en Brown (1937), pp. 101-104, se distinguen otros siete grandes grupos de productos químicos procedentes de la madera. 
como los trapos, la paja o el esparto, de manera que, hacia 1930, casi todo el papel producido en los países desarrollados procedía de la pasta de madera ${ }^{51}$. Así se daba respuesta a una demanda en alza permanente, animada por la rápida expansión de la prensa periódica y de las necesidades de embalaje.

Comparada con la de papel, fue muy secundaria la fabricación (a partir de la pasta de madera) del rayón o seda artificial, que inauguró la era de las fibras sintéticas que iban a revolucionar la industria textil del siglo $\mathrm{xx}$. La utilización del rayón no empezó a tener una mínima entidad hasta la década de 1920; su producción creció con rapidez, pero hacia 1950 sólo representaba una sexta parte de la oferta mundial de fibras textiles, ampliamente dominada, todavía, por el algodón y la lana; y, unos años después, sería desplazado por las fibras propiamente sintéticas (algunos califican al rayón de «semisintético»), entre las cuales destacaban el nailon y la poliamida ${ }^{52}$.

La fabricación de tableros sólo cobró auténtica importancia a partir de 1950, cuando al tablero contrachapado se unieron, primero, los tableros de partículas y, poco después, los de fibras. Pero los comienzos de la utilización de los tableros (con el tablero contrachapado como protagonista en solitario) sí que están dentro del período analizado en este trabajo y merecen un comentario ${ }^{53}$. Con relación a la madera maciza, los tableros (de características semejantes, pese a sus diferentes tipos) presentan ventajas nada desdeñables: regularidad de las dimensiones; mayor calidad de la superficie (siempre lijada) y de los cantos; mucho mejor aprovechamiento de la materia prima; y precio más bajo. Los tableros contrachapados comenzaron a fabricarse en 1896, en Estonia, y su producción aumentó con rapidez en algunos de los países del Báltico (como Finlandia y Rusia), al tiempo que se difundía a otros países ${ }^{54}$. En Europa, al principio, la chapa se obtenía mediante el desenrollo de la madera de abedul de las regiones del citado mar Báltico, pero luego se fue empleando cada vez más la madera de ocume, un árbol que sólo se aprovechaba en Gabón y en el territorio

"1 Gutiérrez (1994); Gutiérrez (1996); Brown (1937), p. 105; Williams (1990), pp. 431-435; Magee (1997), pp. 88-144.

32 Brown (1937), pp. 129-130; Williams (1987), pp. 219-228.

"Nájera (1934), pp. 70-71; Brown (1937), pp. 225-237; Latham (1957), pp. 61-62 y 66; Robert (dir.) (1957), pp. 62-64; FAO (1967), pp. 18-22; Vignote y Jiménez (1996), pp. 233-238; Triboulot y Leban (1998); García Esteban (1999).

${ }^{54}$ En Estados Unidos, por ejemplo, la producción de chapa pasó de 181 millones de pies de tabla de madera en rollo, en 1905, a 1.100 millones, en 1929 [Brown (1937), p. 236]. 
español de Guinea, motivo este último que debió de favorecer la fundación y expansión de la industria de tableros en nuestro país ${ }^{55}$.

Es difícil hacer un balance de todas las transformaciones apuntadas (muy distintas unas de otras) con una información cuantitativa tan escasa. Pero, al menos, pueden sacarse dos conclusiones. La primera es que la madera, lejos de perecer ante el empuje del hierro, del acero y de otros materiales (cuyo empleo ha sido impulsado por los procesos de industrialización), se continúa utilizando actualmente y en cantidades superiores a las de épocas pasadas. Y la segunda es que este mayor volumen de madera se utiliza en nuevas aplicaciones y en usos antiguos renovados, todo ello por las ventajas que siguen teniendo las propiedades de la madera y su propia heterogeneidad, así como por la capacidad de esta materia natural para adaptarse a entornos cambiantes, como lo han sido en todos los órdenes los de los dos últimos siglos.

\section{EL PRODUCTO FORESTAL POR ANTONOMASIA}

Para el período al que se refiere este trabajo (excepto en los últimos años del mismo), no se recogieron los datos de la producción de madera en España ni por el Estado (que sólo se ocupó en sus estadísticas de los montes públicos) ni por institución privada alguna. No obstante, cabe hacerse una idea de la magnitud de dicha producción utilizando los primeros volúmenes de la Estadística Forestal de España, con los cuales se inician las series de las producciones forestales en que ya se tienen en cuenta todos los montes españoles, tanto los públicos como los de particulares. Pero el grado de veracidad de estos datos es muy limitado. En primer lugar, porque se trata de los comienzos de una tarea sin precedentes (en lo relativo a los montes privados, que ocupaban las tres cuartas partes de la superficie forestal), que, además, se emprendió en los años inmediatamente posteriores a la guerra civil, en los cuales los servicios de estadística del Estado franquista no se caracterizaron, precisamente, por su objetividad ni por la suficiencia de los medios técnicos puestos a su alcance. $Y$, en segundo lugar, porque, aun en el supuesto de que no hubieran concurrido las anteriores circunstancias, el minifundismo de los predios fores-

"En España, en 1935, había 17 fábricas de tableros de chapa (o contrachapados) y, en 1957, ya eran 105, pero en este último año sólo existía una fábrica de tableros de fibras y dos de tableros de aglomerado [Arbós (1935), p. 171; Robert (dir.) (1957), p. 62]. 
tales de propiedad privada y, por ende, la gran cantidad de propietarios facilitaban la ocultación total o parcial de muchas cortas.

Estos graves defectos de las cifras de la Estadística Forestal quedaron al descubierto en una de las publicaciones restringidas del Instituto de Cultura Hispánica ${ }^{56}$, en la que se hizo una pormenorizada estimación del consumo de madera en España hacia 1955, concluyéndose que la auténtica producción nacional de madera debía de superar en un 30 por 100 a la producción oficial y que la ocultación, que de este hecho se derivaba, procedía de los montes de particulares, y no de los de utilidad pública, cuyas cifras gozaban de una «indudable exactitud» ${ }^{57}$.

Las mencionadas cifras oficiales y las estimadas se comparan en el Cuadro 3. De su información se desprende (prescindiendo de la diferencia, tal vez excesiva, de las cifras de la tercera columna con relación a las de la primera y segunda ${ }^{58}$ ) que la producción de madera en España a mediados de la década de 1950 debía de rondar los 5 millones de metros cúbicos, de los cuales sólo una quinta parte se habría obtenido en los montes de utilidad pública. Asimismo, se observa que, por la ocultación detectada, habria que incrementar la cifra de la producción oficial de los montes de particulares en más de un 40 por 100 para llegar a la producción real, que sería la estimada en el trabajo del Instituto de Cultura Hispánica.

Esta notable diferencia entre la producción oficial y la real ha sido corroborada de forma implícita por la propia Estadística Forestal, que, desde 1961 hasta el día de hoy, viene añadiendo a los totales nacionales de las producciones obtenidas por los servicios del Ministerio de Agricultura unas cantidades, identificadas como «no incluidas», que no se adjudican a nin-

"6 Robert (dir.) (1957); el capitulo dedicado a «La madera y la celulosa» ocupa las pp. 37-129. Los defectos aludidos ya habían sido objeto de comentario (con un estilo mucho menos directo, desde luego) en Aguado y Foxá (1949), p. 15.

${ }_{57}$ «Las cifras de producción de madera que figuran en las estadísticas publicadas por la Dirección General de Montes, Caza y Pesca Fluvial reflejan con indudable exactitud la cuantía de las cortas en los montes de utilidad pública; en cambio, son inferiores a las reales las relativas a los montes de propiedad particular, integradas por la suma de volúmenes de madera a cortar autorizados por la Administración forestal o declarados, según los casos, por sus propietarios. Como estas cortas particulares corresponden a la mayor parte de los aprovechamientos de madera que se realizan en España y la Administración no puede llegar a la completa inspección y cubicación de los mismos, el error de la referida estadística es importante; por ello, se considera más prudente y real precisar la cifra del consumo actual de madera, las de importación y exportación, para deducir a posteriori la cuantía de las cortas, restando de la cantidad consumida el volumen del saldo importación-exportación» [Robert (dir.) (1957), p. 39].

s* En GEHR (1996b), pp. 86-110, se trata de éste y de otros problemas que plantea la interpretación de los datos de la Estadística Forestal de España. 


\section{CUADRO 3 \\ Datos oficiales y estimados de la producción de madera en España, 1946-1956 \\ (promedios trienales en miles de $m^{3}$ de rollo con corteza)}

\begin{tabular}{|c|c|c|c|}
\hline & $1946-1948$ & 1949-1951 & $1954-1956$ \\
\hline \multicolumn{4}{|l|}{ Datos oficiales de producción } \\
\hline $\begin{array}{l}\text { De los montes de utilidad pública } \\
\text { De los montes de particulares } . . . \ldots \ldots \ldots \ldots \ldots . . . . . . . . .\end{array}$ & $\begin{array}{r}801 \\
1.979\end{array}$ & $\begin{array}{r}760 \\
1.642\end{array}$ & $\begin{array}{l}1.112 \\
2.648\end{array}$ \\
\hline Total (a) ...... & 2.780 & 2.402 & 3.760 \\
\hline \multicolumn{4}{|l|}{ Datos estimados } \\
\hline $\begin{array}{l}\text { Consumo }{ }^{(b)} \\
\text { Importaciones } \\
\text { Exportaciones }^{(c)} \\
\text { Producción }{ }^{(d)}\end{array}$ & & & $\begin{array}{r}5.164 \\
286 \\
21 \\
4.899\end{array}$ \\
\hline Ocultación en datos oficiales ${ }^{(\mathrm{e})}$. & & & 1.139 \\
\hline
\end{tabular}

(a) Suma de la producción de los montes de utilidad pública y de los montes de particulares.

(b) Sólo se refiere a 1955.

(c) Promedio de 1951-1955. Son datos oficiales, no estimados.

(d) Consumo - Importaciones + Exportaciones.

(e) Diferencia entre la producción estimada y la producción total oficial.

FuENTEs: De los datos oficiales, GEHR (1996b), pp. 197 y 199 (la fuente original es la Estadistica Forestal de España), y de los datos estimados, Robert (dir.) (1957), p. 76.

guna provincia ni a ningún tipo de monte y que han de sumarse a los anteriores totales nacionales para obtener la verdadera cuantía del esquilmo en cuestión ${ }^{59}$. Pero adviértase que este apaño de las cantidades adicionales y no distribuidas, aparte de ser un indicador del grado de eficiencia de los funcionarios encargados de la estadística forestal, es un obstáculo insalvable para calcular las auténticas producciones de cada provincia o de cada tipo de monte.

No obstante, las cifras de las décadas de 1940 y 1950 pueden prestar alguna ayuda para establecer la magnitud de la producción maderera total de las provincias antes de 1936, ya que facilitan la proporción que corresponde a los los montes de utilidad pública en la citada producción total.

59 Las primeras cantidades «no incluidas» de madera y leña aparecieron en 1961; las de corcho en 1970; $y$ las de esparto en 1975. 
Estas proporciones son las que figuran en el Cuadro 4 y de ellas se desprende, completando la información del Cuadro 3, que es muy variable (idesde el 0 al 90 por 100!) la importancia relativa de los montes públicos en la producción de madera de las diferentes provincias, circunstancia en la que abunda el Cuadro 5, formado con las principales provincias productoras, de las que puede deducirse el predominio casi absoluto de la propiedad privada en los montes de la provincias gallegas y del litoral can-

\section{CUADRO 4}

Porcentajes medios de la producción de madera de los montes de utilidad pública sobre la producción de madera de todos los montes de la provincia, 1946-1951

\begin{tabular}{|c|c|c|c|c|c|}
\hline Provincia & $1946-1948$ & 1949-1951 & Provincia & $1946-1948$ & 1949-1951 \\
\hline Álava ........ & 10,2 & 19,3 & Lérida................... & 61,4 & 70,6 \\
\hline Albacete ................ & 8,7 & 23,1 & Logroño .............. & 21,0 & 40,9 \\
\hline Alicante ................ & 9,1 & 3,9 & Lugo............... & - & - \\
\hline Almería .................... & 10,2 & 24,5 & Madrid ......... & 50,4 & 43,0 \\
\hline Ávila ........................ & 72,6 & 79,8 & Málaga .................... & 34,3 & 36,8 \\
\hline 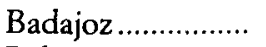 & - & - & Murcia .................. & 15,4 & 11,0 \\
\hline Baleares .................. & 2,4 & 5,0 & Navarra .................. & 71,9 & 66,6 \\
\hline Barcelona .............. & 2,6 & 4,0 & Orense ................... & 3,5 & 4,4 \\
\hline Burgos..................... & 75,5 & 89,7 & 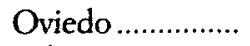 & 2,4 & 2,4 \\
\hline Cáceres ................... & 19,4 & 14,2 & Palencia............... & 24,5 & 38,3 \\
\hline Cádiz....................... & 11,1 & 32,3 & Pontevedra.......... & 3,1 & 7,1 \\
\hline Canarias ............... & 41,5 & 60,7 & Salamanca ........... & 14,5 & 24,6 \\
\hline Castellón................ & 18,3 & 8,9 & Santander............. & 17,5 & 20,1 \\
\hline Ciudad Real.......... & 2,1 & 1,9 & Segovia ................... & 85,4 & 89,9 \\
\hline Córdoba................... & - & - & Sevilla .................. & 15,1 & 27,3 \\
\hline Coruña .................... & - & - & 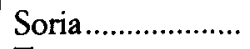 & 83,2 & 84,9 \\
\hline Cuenca.................... & 46,6 & 45,1 & Tarragona ............ & 3,3 & 6,9 \\
\hline 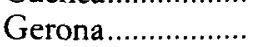 & 6,2 & 6,9 & Teruel................... & 44,7 & 53,0 \\
\hline Granada .................. & 6,2 & 7,1 & Toledo.................. & 3,2 & 2,1 \\
\hline Guadalajara .......... & 60,5 & 67,4 & Valencia............... & 29,6 & 30,2 \\
\hline Guipúzcoa ........... & 10,0 & 25,4 & Valladolid............ & 37,0 & 49,1 \\
\hline Huelva .................... & 19,5 & 20,5 & Vizcaya ................ & 10,8 & 19,9 \\
\hline 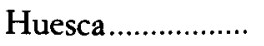 & 54,4 & 62,6 & Zamora................ & 8,8 & 6,5 \\
\hline  & 70,7 & 76,5 & Zaragoza ............... & 12,0 & 39,1 \\
\hline \multirow[t]{2}{*}{ León........................ } & 22,4 & 41,8 & & & \\
\hline & & & España ................. & 28,8 & 31,7 \\
\hline
\end{tabular}

FUENTE: GEHR (1996b), p. 200 (la fuente original es la Estadística Forestal de España). 


\section{CUADRO 5}

Producción de madera en España en todos los montes $y$ en los montes de utilidad pública, 1946-1951 (porcentajes de las provincias más productoras)

\begin{tabular}{|c|c|c|}
\hline Provincia & Todos los montes & M. utilidad pública \\
\hline  & 10,1 & - \\
\hline 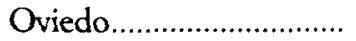 & 6,2 & 0,5 \\
\hline 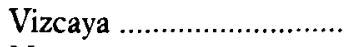 & 5,3 & 2,6 \\
\hline 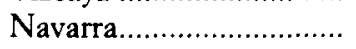 & 5,1 & 11,7 \\
\hline Pontevedra ......................... & 4,6 & 0,8 \\
\hline 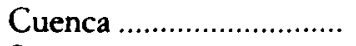 & 4,5 & 6,7 \\
\hline 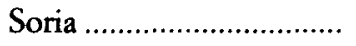 & 4,1 & 11,5 \\
\hline 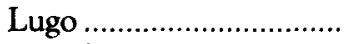 & 3,9 & - \\
\hline 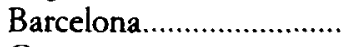 & 3,9 & 0,4 \\
\hline 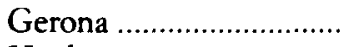 & 3,3 & 0,7 \\
\hline 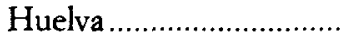 & 3,3 & 2,2 \\
\hline Segovia ........................... & 3,2 & 9,1 \\
\hline 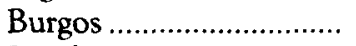 & 3,0 & 8,3 \\
\hline Lérida ............................... & 3,0 & 6,4 \\
\hline Santander ......................... & 2,9 & 1,8 \\
\hline 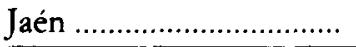 & 2,8 & 13,7 \\
\hline Suma (a).. & 34,8 & 33,8 \\
\hline ..................... & 69,2 & 76,4 \\
\hline 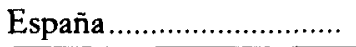 & 100,0 & 100,0 \\
\hline
\end{tabular}

(a) Suma de las siete primeras provincias.

(b) Suma de las dieciséis provincias consideradas, que son las que aportan el 2,5 o más por 100 a la producción de madera de todos los montes.

FUENTE: GEHR (1996b), pp. 198 y 201 (la fuente original es la Estadística Forestal de España).

tábrico, así como la situación inversa en el interior de la península, representado por Cuenca, Soria y Segovia.

Pero el mencionado Cuadro 5 también pone de manifiesto una elevada concentración espacial de la producción maderera, ya que una tercera parte de la misma se obtiene en 7 provincias ( 4 del nordeste y 3 de la submeseta norte), proporción que llega al 70 por 100 , si, en vez de 7 , se consideran 16 provincias, que vienen a reforzar la supremacía maderera del cuadrante 
noroccidental de la península, al que se añadiría Cataluña, por el nordeste, y Huelva y Jaén (auténticos islotes) por el sur. Es de señalar, asimismo, que la citada concentración espacial es un atributo propio del conjunto de los montes y del subconjunto de los de utilidad pública. Pero de éstos se tratará más detenidamente en el siguiente subepigrafe.

\subsection{La producción de madera en los montes de utilidad pública}

Un resumen de los diferentes aspectos de la producción de madera en los montes de utilidad pública, durante el primer tercio del siglo $\mathrm{xx}$, se ofrece en el Cuadro 6. Lo primero que llama la atención es el considerable incremento de la producción, tanto en unidades físicas como en valor, debido (como atestigua el Cuadro 7 , si se dan por buenas sus cifras ${ }^{60}$ ), no a la expansión de las superficies aprovechadas, sino a un alza de los rendimientos, que, para el conjunto de España, llegaron a duplicarse en el corto período de dos décadas, a lo que habría contribuido el mejor tratamiento forestal que acompañó al avance de la superficie sometida a ordenación, que pasó de $140.000 \mathrm{Ha}$., en 1903, a 600.000, en $1932^{61}$.

Pero el Cuadro 6 confirma la intensa concentración espacial de la producción, ya aludida más arriba, y añade una interesante información sobre este hecho, al agrupar a las provincias en tres conjuntos. El Conjunto 1 (con 8 provincias, solamente) sería el de mayor producción, con diferencia, aunque sus elevados porcentajes vayan disminuyendo a medida que van aumentando los del Conjunto 2 (formado por 10 provincias, casi todas levantinas), que experimentó un rapidísimo crecimiento desde cantidades iniciales insignificantes. Y, por último, está el Conjunto 3, el más extenso (comprende cerca de 30 provincias, ya que Navarra y el País Vasco no

Los datos de las superficies aprovechadas presentan anomalías que hacen dudar de su veracidad. Adviértase, no obstante, que estas anomalias pueden ser debidas a defectos en la cuantificación de la superficie aprovechada y, también, a las diferentes características de los poblamientos, especialmente a las que pudieran existir entre los predios tradicionalmente madereros y los más nuevos, donde comenzaba a obtenerse madera como resultado de las repoblaciones. Además, las citadas anomalías hacen que los rendimientos de las producciones forestales por unidad de superficie (a diferencia de lo que suele suceder en la agricultura) sean un indicador engañoso, que debe ser utilizado con cautela.

${ }_{61}$ GEHR (1991), p. 1197. En Robert (dir.) (1957), pp. 87-93, se afirma que las ordenaciones traen consigo un notable incremento de la producción de madera, «hasta casi triplicarse». 


\section{CUADRO 6}

Producción de madera en los montes de utilidad pública de España, 1903-1932 (unidades físicas y valor)

\begin{tabular}{|c|c|c|c|c|}
\hline & 1903 & 1913 & 1920 & 1932 \\
\hline \multicolumn{5}{|l|}{ Unidades físicas (miles $\mathrm{m}^{3}$ ) } \\
\hline $\begin{array}{l}\text { Conjunto } 1 \\
\text { Conjunto } 2 \\
\text { Conjunto } 3\end{array}$ & $\begin{array}{r}152 \\
19 \\
29\end{array}$ & $\begin{array}{r}204 \\
47 \\
39\end{array}$ & $\begin{array}{r}177 \\
94 \\
79\end{array}$ & $\begin{array}{r}259 \\
175 \\
78\end{array}$ \\
\hline España .. & 200 & 290 & 350 & 512 \\
\hline
\end{tabular}

Unidades físicas (\% sobre España)

\begin{tabular}{|c|c|c|c|c|}
\hline Conjunto 1 & 76,0 & 70,3 & 50,6 & 50,6 \\
\hline Conjunto 2 & 9,5 & 16,2 & 26,9 & 34,3 \\
\hline Conjunto 3 & 14,5 & 13,4 & 22,6 & 15,2 \\
\hline . & 100,0 & 100,0 & 100,0 & 100,0 \\
\hline
\end{tabular}

Unidades físicas (índices) (base 100 en 1903)

Conjunto 1

Conjunto 2

Conjunto 3

\begin{tabular}{|c|c|c|c|}
\hline 100 & 134 & 116 & 170 \\
\hline 100 & 247 & 495 & 921 \\
\hline 100 & 134 & 272 & 269 \\
\hline 100 & 145 & 175 & 256 \\
\hline
\end{tabular}

España

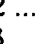



Valor (miles ptas. de 1913)

Conjunto 1

Conjunto 2

Conjunto 3

España

\begin{tabular}{rrr}
1.540 & 1.238 & 2.329 \\
420 & 545 & 1.644 \\
366 & 493 & 822 \\
\hline 2.326 & 2.276 & 4.795
\end{tabular}

Valor (\% sobre España)

Conjunto 1

Conjunto 2

Conjunto 3

España

\begin{tabular}{rrr}
66,2 & 54,4 & 48,6 \\
18,1 & 23,9 & 34,3 \\
15,7 & 21,7 & 17,1 \\
\hline 100,0 & 100,0 & 100,0
\end{tabular}

Valor (índices) (base 100 en 1913)

Conjunto 1

Conjunto 2

Conjunto 3

\begin{tabular}{rrrr}
100 & 80 & 151 \\
100 & 130 & 391 \\
100 & 135 & 225 \\
\hline 100 & 98 & 206 \\
\hline
\end{tabular}

España



ca, Huesca, Jaén, Segovia y Soria.

Conjunto 1: Abacete, Avila, Burgos, Cuenca, Hueares, Barcelona, Castellón, Gerona, Huelva, Lérida, Sevilla, Tarragona, Teruel y Valencia.

Conjunto 3: Resto de las provincias, menos Navarra y País Vasco, que no son consideradas por la fuente original.

FUENTE: GEHR (1991), cuadro 18. 


\section{CUADRO 7}

Superficie forestal aprovechada de madera y sus rendimientos en los montes de utilidad pública de España, 1903-1920

\begin{tabular}{|c|c|c|c|}
\hline & 1903 & 1913 & 1920 \\
\hline \multicolumn{4}{|l|}{ Superficie aprovechada (miles $\mathrm{Ha}$ ) } \\
\hline 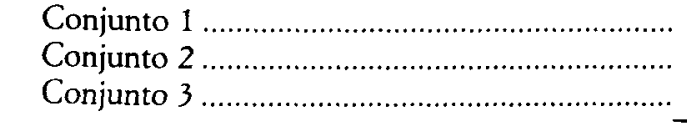 & $\begin{array}{r}54 \\
7 \\
12 \\
\end{array}$ & $\begin{array}{l}61 \\
11 \\
19 \\
\end{array}$ & $\begin{array}{l}48 \\
10 \\
14\end{array}$ \\
\hline España & 73 & 91 & 72 \\
\hline \multicolumn{4}{|l|}{ Superficie aprovechada (\% sobre España) } \\
\hline $\begin{array}{l}\text { Conjunto } 1 \\
\text { Conjunto } 2 \\
\text { Conjunto } 3\end{array}$ & $\begin{array}{r}74,0 \\
9,6 \\
16,4 \\
\end{array}$ & $\begin{array}{l}67,0 \\
12,1 \\
20,9 \\
\end{array}$ & $\begin{array}{l}66,7 \\
13,9 \\
19,4\end{array}$ \\
\hline 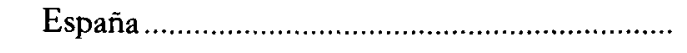 & 100,0 & 100,0 & 100,0 \\
\hline \multicolumn{4}{|l|}{ Superficie aprovechada (índices) (base 100 en 1903) } \\
\hline $\begin{array}{l}\text { Conjunto } 1 \\
\text { Conjunto } 2 \\
\text { Conjunto } 3\end{array}$ & $\begin{array}{l}100 \\
100 \\
100\end{array}$ & $\begin{array}{l}113 \\
157 \\
158 \\
\end{array}$ & $\begin{array}{r}89 \\
143 \\
117 \\
\end{array}$ \\
\hline 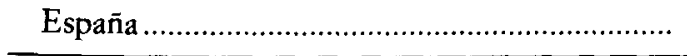 & 100 & 125 & 99 \\
\hline \multicolumn{4}{|l|}{ Rendimientos $\left(\mathrm{m}^{3} / \mathrm{Ha}\right)$} \\
\hline $\begin{array}{l}\text { Conjunto } 1 \\
\text { Conjunto } 2 \\
\text { Conjunto } 3\end{array}$ & $\begin{array}{l}2,8 \\
2,7 \\
2,4 \\
\end{array}$ & $\begin{array}{l}3,3 \\
4,3 \\
2,1 \\
\end{array}$ & $\begin{array}{l}3,7 \\
9,4 \\
5,6 \\
\end{array}$ \\
\hline España... & 2,7 & 3,2 & 4,9 \\
\hline
\end{tabular}

Conjunto 1: Albacete, Ávila, Burgos, Cuenca, Huesca, Jaén, Segovia y Soria.

Conjunto 2: Baleares, Barcelona, Castellón, Gerona, Huelva, Lérida, Sevilla, Tarragona, Teruel y Valencia.

Conjunto 3: Resto de las provincias, menos Navarra y País Vasco, que no son consideradas por la fuente original.

FUENTE: GEHR (1991), cuadros 16 y 18.

son considerados por la fuente), pero con una importancia maderera muy escasa, que apenas se modifica en el período estudiado.

En los Conjuntos 1 y 2 aparecen las provincias más productoras, identificadas en el Cuadro 5, con las notables excepciones de las provincias gallegas y cantábricas que allí se mencionaban. En consecuencia, la dis- 
tribución espacial de la producción madera de los montes de utilidad pública sólo coincide parcialmente con la resultante de la producción de todos los montes. $\mathrm{Y}$ también son dignas de mención las diferencias entre los rendimientos de los tres conjuntos, como se puede apreciar en el Cuadro 7. Todos comienzan con un nivel análogo y mejoran en las dos primeras décadas del siglo $\mathrm{xx}$, pero en muy distintas proporciones. Mientras que los rendimientos de la zona maderera tradicional (el Conjunto 1) se incrementan un 30 por 100 , los de la nueva zona maderera (el Conjunto 2) se multiplican por 3,5 .

Por último, se presentan los Cuadros 8 y 9 , a fin de comparar la evolución de la madera con la seguida por los demás aprovechamientos forestales. La información de estos cuadros es discontinua, porque no se refieren a la misma superficie, pero sus datos reflejan con claridad que la «ma-

\section{CUADRO 8}

Producción de los montes de utilidad pública de España, 1901-1933 (valor de la producción y números indices de las unidades físicas) (promedios quinquenales)

\begin{tabular}{lrrrrrrrr}
\hline & Madera & Leña & Pastos & Esparto & Resina & $\begin{array}{c}\text { Corcbo y } \\
\text { cortezas }\end{array}$ & $\begin{array}{c}\text { Rotura } \\
\text { ciones }\end{array}$ & Total \\
\hline (a) & & & & & & & & \\
$1901-1905 \ldots \ldots \ldots$. & 1.324 & 1.037 & 4.622 & 160 & 804 & 211 & - & 8.157 \\
$1916-1920 \ldots \ldots \ldots$. & 2.414 & 985 & 5.025 & 165 & 1.568 & 308 & 49 & 10.514 \\
$1929-1933 \ldots \ldots \ldots$. & 3.837 & 1.082 & 5.767 & 273 & 2.853 & 1.459 & 296 & 15.567 \\
\hline (b) & & & & & & & & \\
$1901-1905 \ldots \ldots \ldots$ & 16,2 & 12,7 & 56,7 & 2,0 & 9,9 & 2,6 & - & 100,0 \\
$1916-1920 \ldots \ldots \ldots$. & 23,0 & 9,4 & 47,8 & 1,6 & 14,9 & 2,9 & 0,5 & 100,0 \\
$1929-1933 \ldots \ldots \ldots$. & 24,7 & 7,0 & 37,0 & 1,8 & 18,3 & 9,4 & 1,9 & 100,0 \\
\hline (c) & & & & & & & & \\
$1901-1905 \ldots \ldots \ldots$ & 100 & 100 & 100 & 100 & 100 & 100 & & 100 \\
$1916-1920 \ldots \ldots \ldots$. & 182 & 95 & 109 & 103 & 195 & 146 & 100 & 129 \\
$1929-1933 \ldots \ldots \ldots$. & 290 & 104 & 125 & 171 & 355 & 691 & 407 & 191 \\
\hline
\end{tabular}

(a) Producción media anual valorada con los valores medios de 1913 (miles ptas.). total.

(b) Porcentaje de cada producto (valorado con los valores medios de 1913) sobre el

(c) Números índices de la producción medida en unidades físicas (base 100 en 1903.1907).

FUENTE: GEHR (1996c), p. 10. 


\section{CUADRO 9}

Valor de la producción de todos los montes de España, 1946-1979 (millones de pesetas de 1959) (promedios decenales)

\begin{tabular}{rrrrrrrrr}
\hline & Madera & Leña & Pastos & Esparto & Resina & Corcho & Frutos & Total \\
\hline $1946-1955 \ldots \ldots . . .$. & 1.524 & 390 & 2.739 & 171 & 102 & 175 & 920 & 6.021 \\
$1970-1979 \ldots \ldots . . .$. & 4.664 & 121 & 4.440 & 7 & 135 & 378 & 521 & 10.266 \\
\hline
\end{tabular}

(a)

1946-1955.

\begin{tabular}{rrrrrrrr}
25,3 & 6,5 & 45,5 & 2,8 & 1,7 & 2,9 & 15,3 & 100,0 \\
45,4 & 1,2 & 43,2 & 0,1 & 1,3 & 3,7 & 5,1 & 100,0 \\
\hline
\end{tabular}

(b)

\begin{tabular}{lllllllll}
$1970-1979 \ldots \ldots \ldots$ & 306 & 31 & 162 & 4 & 132 & 216 & 57 & 171 \\
\hline
\end{tabular}

(a) Porcentaje de cada producto sobre el total.

(b) Números índices de 1970-1979 (base 100 en 1946-1955).

FuENTE: Zambrana (1998), p. 10 (la fuente original es la Estadística Forestal de España).

derización» de la producción forestal (la transformación de mayor alcance ocurrida en los bosques españoles en el presente siglo, especialmente en su segunda mitad) ya había comenzado en las primeras décadas del citado siglo y estaba afianzada hacia $1950^{62}$. En efecto, los datos del primer tercio del siglo xx (del Cuadro 8) dejan ver una multifuncionalidad propia del bosque mediterráneo, pero con elocuentes variaciones en los porcentajes de los aprovechamientos, ya que los incrementos de los más vinculados a los mercados (como la madera, la resina y el corcho) son simultáneos al descenso de los dedicados al autoconsumo y a los usos vecinales (como los pastos y la leña ${ }^{63}$ ). Y estas tendencias, que todavía formaban parte de una sector agrario tradicional, se aceleraron en las décadas posteriores a la guerra civil (como se ve en el Cuadro 9), sobre todo desde que la llamada «crisis de la agricultura tradicional» empezara a trastocar la economía, los comportamientos sociales y hasta el paisaje que había caracterizado durante siglos a las zonas rurales de nuestro país. Así, la producción de los montes españoles, pese al crecimiento del total, ha quedado restringida (con la consiguiente pérdida de multifuncionalidad) a los aprovechamientos de madera, pastos y praderas (que suman el 90 por 100

\footnotetext{
${ }^{62}$ GEHR (1996a); GEHR (1996b); GEHR (1996c); Zambrana (1998).

63 Aquí se aprecia bien la diferencia entre los aprovechamientos de madera y leña, señalada en el anterior epígrafe.
} 
del producto forestal total), a los que acompañan esquilmos menores y muy localizados, como el corcho y los frutos. De esta forma, y pese al carácter mediterráneo de gran parte de nuestra superficie boscosa, la madera también ha llegado a ser en España (como preconizaban los manuales de dasonomía, de inspiración germana, y numerosos ingenieros del ramo) el producto forestal por antonomasia.

\subsection{Una estimación de la producción de madera en España durante el primer tercio del siglo $\mathrm{Xx}$}

Con este subepígrafe me propongo establecer de forma aproximada la magnitud de la producción total de madera al principio y al final del primer tercio del siglo $\mathrm{xx}$, para cotejar las cifras resultantes con las de otras variables, como las procedentes del comercio exterior, $y$, de ese modo, hacer algunas consideraciones sobre la problemática de la madera en España, yendo un poco más allá de la información que proporciona el parcial indicador de los aprovechamientos de los montes de utilidad pública. Sin embargo, reconozco los muchos inconvenientes del método empleado (por el excesivo número de supuestos en que se apoya) y confío en que pronto pueda disponerse de cifras más veraces. El método en cuestión (que se expone en el Apéndice) consiste en una estimación indirecta de la producción por medio del consumo, siguiendo, con pocas modificaciones, el procedimiento empleado en la publicación, ya citada, del Instituto de Cultura Hispánica para los años 1951-1955 ${ }^{64}$.

En el Cuadro 10 se presentan los resultados de la estimación realizada. Las cifras obtenidas salen airosas de dos pruebas. La primera es la semejanza entre las importaciones de 1931.1935 calculadas en el Apéndice y las correspondientes cantidades que se facilitan en Robert (dir.) (1957) ${ }^{65}$. Y la segunda prueba es el porcentaje que representa la producción de los montes de utilidad pública sobre la producción total estimada, que se mantiene entre el 20 y el 24 por 100 , una proporción que concuerda con la diferencia superficial que existe entre el conjunto de todos los montes y el subconjunto de los gestionados por la administración pública.

El incremento de la producción de madera, en el primer tercio del siglo $\mathrm{xx}$, es bien llamativo. Su volumen se duplicó, con creces. Ninguno

${ }^{64}$ Robert (dir.) (1957), pp. 39.70.

65 En Robert (dir.) (1957), p. 79, dichas importaciones ascienden a 1.571 miles de $\mathrm{m}^{3}$ de rollo sin corteza, y en el Apéndice a 1.633 miles de $\mathrm{m}^{3}$ de rollo con corteza. 
de los grandes cultivos del sector agrario español tuvo una evolución tan expansiva. En el caso de los montes públicos, parece (como ya dije más arriba, al comentar el Cuadro 7) que el alza de los rendimientos fue la principal causa del crecimiento de la producción, y que dicha alza estaría relacionada con la ampliación de los terrenos sujetos a ordenación. Sobre los montes pertenecientes a particulares (que eran la mayoría en número y extensión) no se puede hacer, de momento, una afirmación semejante, por una carencia casi absoluta de información.

No obstante, cabe formular algunas hipótesis explicativas del aumento de la producción de madera en el conjunto de los terrenos forestales, tanto públicos como privados. Pero antes es imprescindible hacer unas consideraciones relativas a las condiciones generales en que se desenvolvían los mercados internacionales de madera y a las peculiaridades del caso español, que es el que interesa ahora ${ }^{66}$.

El rasgo que caracteriza de forma dominante a la comercialización de la madera, ya sea en España o en el extranjero, es la diversidad. Existían mercados muy distintos de productos también muy distintos, donde se empleaban diferentes unidades de medida y donde apenas se había esta-

\section{CUADRO 10}

Producción, consumo e importaciones netas de madera en España, 1900-1955 (promedios quinquenales)

\begin{tabular}{|c|c|c|c|}
\hline & $1900-1904$ & $1931-1935$ & $1951-1955$ \\
\hline \multicolumn{4}{|l|}{ Unidades físicas (miles $\mathrm{m}^{3}$ rollo con corteza) } \\
\hline 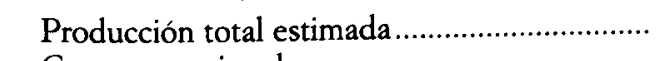 & 987 & 2.170 & 4.899 \\
\hline 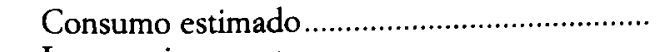 & 1.907 & 3.700 & 5.164 \\
\hline 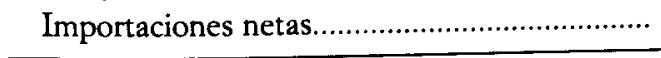 & 920 & 1.530 & 265 \\
\hline \multicolumn{4}{|l|}{ Números índices (base 100 en 1900-1904) } \\
\hline Producción total estimada .................................. & 100 & 220 & 496 \\
\hline 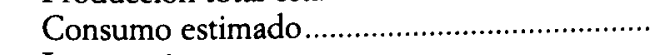 & 100 & 194 & 287 \\
\hline 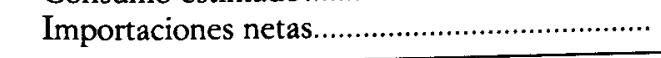 & 100 & 166 & 29 \\
\hline \multicolumn{4}{|l|}{ Porcentajes } \\
\hline $\begin{array}{l}\text { Prod. montes utilidad pública sobre produc- } \\
\text { ción estimada }\end{array}$ & 20 & 24 & 23 \\
\hline Importaciones netas sobre consumo estimado. & 48 & 41 & 5 \\
\hline
\end{tabular}

FuENTES: Apéndice; Cuadro 6; GEHR (1996b), p. 199.

tó En los siguientes párrafos haré un resumen del capítulo 6 de Zapata (1998). 
blecido una normalización de los productos, de lo cual se derivaba una notable merma de la transparencia con que se realizaban las correspondientes transacciones.

Sobre la evolución de la economía internacional de la madera durante el período del que trata el artículo, sólo he podido determinar algunas de sus principales tendencias, que expongo a continuación. América del Norte entró en el comercio europeo (mejor sería decir británico) de maderas en el primer tercio del siglo XIX, con motivo de las guerras napoleónicas, que impidieron el normal abastecimiento de Gran Bretaña por parte de los países del Báltico, en particular, de Noruega ${ }^{67}$. Más adelante, en la década de 1860, en Gran Bretaña se tomaron diversas medidas (como la supresión de algunos impuestos y de la preferencia colonial) que estimularon la producción y el comercio en los países del Báltico, especialmente en Suecia, que enseguida pasó a ser el primer abastecedor del mercado británico (por delante de Canadá y Noruega) de maderas blandas de coníferas y cuya industria maderera se expandió y consolidó en el último cuarto del siglo $x{ }^{68}$. Simultáneamente, se fue incrementando la oferta de maderas duras de frondosas (mucho menos utilizadas que las de coniferas, no se olvide), procedentes de la Europa central y meridional y, en particular, de Yugoslavia ${ }^{69}$.

Ahora bien, el cambio más trascendental que se registró en la economía internacional maderera, en el período del que se ocupa este trabajo, fue la creciente participación en el comercio europeo de Rusia y, luego, de la Unión Soviética. A finales del siglo pasado, las maderas rusas comenzaron a llegar en cantidades dignas de mención a muchos mercados de la Europa occidental ${ }^{70}$. Pero la influencia rusa se haría notar mucho más, después, cuando su ingente potencial maderero se incrementó con la creación de la Unión Soviética ${ }^{71}$. En el mundo de la madera, la Unión Soviética era un coloso y todos los demás enanos. A la Unión Soviética correspondía

67 Según Latham (1957), p. 48, de finales del siglo xviı a 1833, las importaciones británicas de madera se multiplicaron por más de 2; en los primeros años, toda la madera (salvo una porción ínfima) venía del Báltico; pero, desde 1808 en adelante, fueron las «colonias británicas de Norteamérica» la procedencia de más de las dos terceras partes de las importaciones.

(** Latham (1957), pp. 56-57, 98 y 100; Mitchell (1992), pp. 402-405.

${ }^{69}$ Latham (1957), p. 205.

70 Björklund (2000). En vísperas de la Primera Guerra Mundial, Rusia ya estaba a la cabeza de los exportadores europeos con unas cantidades anuales próximas a los 7 millones de $\mathrm{m}^{3}$, casi todos ellos de coniferas [Latham (1957), p. 99].

11 Pitter (1932); Nájera (1934), p. 11; Arbós (1935), pp. 13-30; «L'organisation...» (1936); Latham (1957), p. 63. 
nada menos que las dos terceras partes de toda la superficie forestal arbolada de Europa, que, además, estaba subexplotada, a diferencia de lo que sucedía en otras grandes naciones exportadoras, como Suecia, Noruega y, sobre todo, los Estados Unidos ${ }^{72}$. Y, por si esto fuera poco, había pruebas de que el gobierno soviético estimulaba la producción y las exportaciones de madera para financiar inversiones del plan quinquenal, que, por entonces, daba sus primeros pasos ${ }^{73}$.

España era, sin duda, uno de los enanos mencionados, y de los más pequeños entre los países europeos. Era un país netamente importador, pues su tasa de cobertura se mantuvo en niveles ínfimos, por debajo del 10 por 100 , salvo en situaciones excepcionales (como los últimos años del siglo XIX, de la crisis agropecuaria, y los de la primera guerra mundial), en que dicha tasa fluctuó alrededor del 30 por $100^{74}$. Las importaciones de madera ocupaban un lugar muy destacado en nuestro comercio exterior. Por su valor, estaban en el segundo puesto entre todas las importaciones españolas (después del algodón en rama) y tenían porcentajes análogos a los de partidas como el trigo, el carbón o la maquinaria ${ }^{75}$.

En total, la mitad de la madera consumida en España tenía que venir del extranjero. Sin embargo, existía una perfecta complementariedad entre la producción interior y las maderas importadas. Aquélla se destinaba a postes, envases y embalajes y, en menor medida, a la construcción y a traviesas de ferrocarril; mientras que la madera extranjera iba en un 80 por 100 para la construcción y la carpintería ${ }^{76}$. Así se entiende mejor que, pese a tratarse de unas importaciones tan cuantiosas y crecientes, la madera sin elaborar tuviera un nivel de protección muy por debajo de la media ${ }^{77}$.

72 Arbós (1935), pp. 24-26.

73 Pitter (1932).

74 Para calcular esta tasa y los demás datos relativos a las importaciones o exportaciones españolas de maderas que aparecen en el artículo, he utilizado las series elaboradas por Domingo Gallego y Vicente Pinilla.

${ }^{75}$ Prados (1982), p. 53

76 Arbós (1935), pp. 287 y 298; Robert (dir.) (1957), pp. 122 y 126. En estas últimas páginas, se dice: «España fue siempre un país importador de cantidades considerables de madera y de pastas celulósicas [...] La mayor parte de la madera producida en España, más del 70 por 100 , es de mala calidad y apropiada, preferentemente, para minas, envases y celulosas [...] Estos tres consumos concurren entre sí en el mercado por utilizar los mismos rollizos en especie, calidad y diámetros [...] Las importaciones de madera realizadas tradicionalmente en España han sido siempre, en su mayoría, de madera de construcción.» Asimismo, Gallego y Pinilla (1996), pp. 381-383 y 389, incluyen las importaciones de madera sin labrar (la destinada a la construcción y carpintería) dentro del grupo de los «productos agrarios no competitivos con la producción interior», en el que la producción local y las compras al extranjero se complementaban mutuamente.

77 La escasa protección de las importaciones de madera, comparada con la de otros productos agrarios, se deduce de Gallego (1998). 
Los mercados españoles de maderas presentaban singularidades que también deben tenerse en cuenta ${ }^{78}$. Los oferentes de maderas eran (y son) legión en España, donde la propiedad forestal tenía (y tiene) un marcado carácter minifundista ${ }^{79}$, por lo que se hacía necesaria la figura del intermediario para poner en contacto a la multitud de pequeños productores con los demandantes, un grupo reducido y heterogéneo compuesto por las empresas del aserrío y de todas las industrias derivadas de la madera, así como por los almacenistas situados en los puntos de consumo. Pero en este esquema hay que introducir al Estado, que, como se sabe, era propietario-administrador de una cuarta parte de los terrenos forestales españoles y actuaba como oferente de madera en unas condiciones especiales ${ }^{80}$. En consecuencia, deben distinguirse dos mercados de maderas distintos, aunque relacionados entre sí en un grado muy difícil de precisar: uno, libre (el adjetivo es capcioso, pero expresivo), y otro, intervenido ${ }^{81}$.

La intervención del Estado en los montes públicos era muy variada y aquí sólo haré mención de las actuaciones que podían afectar a las condiciones de oferta y demanda de productos forestales, en general, y de la madera, en particular. Y, a tal efecto, conviene distinguir entre la administración central y la municipal.

Muchas de las tareas encomendadas a la administración central en los montes públicos tenían repercusiones directas en el funcionamiento de los mercados de productos forestales. Las medidas conservacionistas (declaración de montes enajenables o exceptuados de la venta o de montes protectores) ponían a ciertas masas, total o parcialmente, en circunstancias distintas a las del mercado libre, lo cual se plasmaba en la regulación de los aprovechamientos, que podía tener diferentes fórmulas (desde los usos vecinales a la ordenación) y que, a su vez, podían aplicarse con muy diversa intensidad según las características ecológicas y sociales de cada espacio forestal. A medida que los planes de aprovechamiento y ordenación se ejecutaran con más rigor y se generalizara la práctica de las subastas para acceder al disfrute de los aprovechamientos, no sólo se estaban modificando la cantidad y la calidad de la oferta y sus precios, sino que también se

${ }^{78}$ En lo relativo a este punto, tomaré prestadas muchas ideas de Iriarte (1995), pp. 545-702.

${ }^{79}$ Robert (dir.) (1957), pp. 30-33; Vignote y Jiménez (1996), p. 26.

${ }^{80}$ Estoy considerando al Estado de un modo genérico, formado por todas las administraciones públicas de cualquier tipo y territorio.

${ }^{8}$ La intervención el Estado en los montes de particulares, durante el período que se contempla en este trabajo, fue prácticamente nula. 
estaba actuando sobre los demandantes, dando más facilidades a unos que a otros para la adquisición de los esquilmos.

Y otra faceta de la intervención de la administración central con gran repercusión en la oferta de productos forestales (de madera, especialmente) fue la repoblación forestal. Bien es cierto que, en el período estudiado, estas inversiones fueron de escasa cuantía, que tuvieron un objetivo más protector que productor, y que he renunciado, por ahora, al análisis de los vínculos existentes entre la política y la práctica de las repoblaciones con la economía de la madera en España, por las limitaciones de este trabajo, ya enunciadas en los párrafos introductorios. Sin embargo, hay suficientes indicios de que fue en el primer tercio del siglo $\mathrm{xx}$ cuando se pusieron las bases doctrinales, jurídicas e institucionales de la ingente obra repobladora que se llevaría a cabo después de la guerra civil ${ }^{82}$.

Junto a la central, la administración municipal (representante de las instituciones propietarias de la mayor parte de los montes públicos) también podía modificar las circunstancias de la oferta y la demanda, reservando para los vecinos de los pueblos una parte o la totalidad de ciertos aprovechamientos (de forma gratuita o con precios mucho más bajos de los que regían en los mercados) o cobrando un canon por ciertos disfrutes, cuya variación, por lo general, dependía más de las necesidades presupuestarias de cada ayuntamiento que de la evolución de las cotizaciones en las plazas que marcaran la pauta de los productos correspondientes. Ahora bien, todas las formas descritas de la intervención del Estado, llevadas a cabo por cualquiera de los escalones de la administración pública, se concretaron de forma muy diferente. Los mismos organismos y los mismos funcionarios aplicaron de diferente manera la misma normativa (llegándose a resultados distintos, claro está), según las características sociales, económicas y ecológicas del lugar, del momento y del aprovechamiento objeto de regulación. La diversidad, y no la uniformidad, fue la norma, aunque, eso sí, dentro de un orden ${ }^{83}$.

Aparte de la intervención del Estado, cuyos efectos trascendían el ámbito de los montes públicos donde se ejercía, otras circunstancias influían en la evolución de la oferta y la demanda de productos forestales ( $y$, de madera, en particular) en toda clase de terrenos boscosos. La primera de

${ }^{* 2}$ Rico (1999). En este trabajo, también se proporciona una información cuantitativa que pone en tela de juicio (por lo menos, para el caso de Pontevedra) la idea expresada de la escasa importancia de las repoblaciones forestales, llevadas a cabo por particulares, durante el primer tercio del siglo $\mathrm{xx}$.

${ }^{83}$ GEHR (1999). 
dichas circunstancias era la composición física de los montes (situación, tipo de suelo, especies arbóreas, poblamiento, etc.), cuya influencia en la explotación económica de un predio podía ser decisiva. Y relacionadas con estas características físicas estaban las condiciones de obtención de los productos. El difícil acceso a los montes, la estacionalidad de la mayoría de los aprovechamientos y la utilización casi exclusiva de la mano de obra y de la fuerza de tracción animal (por los escasos progresos que había registrado la mecanización de las tareas forestales) limitaban total o parcialmente la explotación de muchos montes ${ }^{84}$. De todos estos problemas, el de los transportes era, sin duda, el de mayor importancia y el que más directamente afectaba al funcionamiento de los mercados y a la marcha de los precios. El estado de los transportes forestales en España, bien entrado ya el siglo $\mathrm{xx}$, era lamentable, hasta el punto de que nuestros ríos ( $\tan$ pequeños e irregulares) eran un medio de transporte más eficaz para las maderas que la carretera e, incluso, que el ferrocarril ${ }^{85}$.

Por último, los demandantes ejercían una influencia decisiva en los mercados de maderas. En el período analizado, se produjeron profundos cambios en la cantidad y en el tipo de madera demandada por la industria. Pero de este asunto, aunque sea de forma indirecta, ya se ha tratado en un epígrafe anterior y al mismo me remito.

De lo dicho hasta aquí se desprende que los mercados españoles de maderas (intervenidos o libres) eran mercados fragmentados, que se desenvolvían en condiciones muy distintas a las que, por las mismas fechas, caracterizaban a otros mercados de productos agrarios, mucho más integrados, como eran los del trigo o el del aceite de oliva, y que dicha fragmentación (a juzgar por los análisis de precios que se han podido llevar a cabo) persistió durante las tres primeras décadas del siglo $\mathrm{xx}^{86}$.

Ahora, teniendo ya una idea (por vaga que sea) sobre las características de los mercados interiores e internacionales de maderas, formularé la anun-

${ }^{84}$ En Estados Unidos, se utilizó, por primera vez, el cable aéreo en 1883, y el tractor forestal a vapor en 1893 [Latham (1957), pp. 122-123].

*5 Baró (1920); «Los madereros...» (1891); Baró (1914); Mantilla (1931); Hollister-Short (1994); Pinilla (1995b), pp. 427-439; Sabio (1997), pp. 57-77.

* En 1902, la Revista de Montes publicó, en su recién estrenada «Sección mercantil», un breve, pero enjundioso, informe sobre la comercialización de las maderas en España, que terminaba con estas expresivas palabras: «El mercado de maderas es [...] en España muy imperfecto y no es raro apreciar en sitios próximos diferencias notabilísimas en el precio de este producto. Dedúcese de lo expuesto que las maderas de Suecia y Noruega comparten con las de Balsaín [sic], y aun podemos decir con las de Soria, Burgos, Cuenca y Teruel la primacía para los trabajos de carpintería fina, y que la dificultad de los transportes y lo elevado de las tarifas de los ferrocarriles son causa de que ejerza aún poca influencia el precio de un mercado en el de los demás [...] hoy no es posible estudiar [el mercado 
ciada hipótesis explicativa del incremento de la producción de madera en España. Se sabe que en las tres primeras décadas del siglo xx hubo profundas transformaciones en el uso del suelo, de manera que unos 4 millones de hectáreas, calificadas de «montes, dehesas y pastos», fueron roturadas y convertidas en nueva superfice agrícola ${ }^{87}$. En consecuencia, sería contradictorio argumentar que el crecimiento de la madera producida en nuestros bosques se haya debido a una mera ampliación de la superficie aprovechada, cuando más bien parece que ésta debió de disminuir, por lo cual parece que fue una mejora de los rendimientos (como en el caso de los montes de utilidad pública) la principal causante del aumento de la producción.

Pero, tratándose de un esquilmo forestal como la madera, unos rendimientos más altos pueden obtenerse de diversas formas, con repercusiones muy diferentes sobre el ecosistema que se está explotando. Así, por ejemplo, puede obtenerse una mayor cantidad de madera por unidad de superficie innovando los tratamientos selvícolas, o repoblando zonas desarboladas, o introduciendo distintas especies arbóreas (sean o no exóticas) o haciendo cortas selectivas y sistemáticas que vayan rejuveneciendo los poblamientos de bosques tradicionales. En mi opinión, todo esto (incluidos los descuajes) se puso en práctica en diferentes grados, según el momento y el lugar, y fue la causa inmediata del incremento de la producción.

Estos cambios en la oferta estuvieron animados por una veloz subida del consumo (como correspondía a un país en vías de industrialización) y por unos precios relativos (respecto al hierro y otros materiales de construcción) muy favorables para la madera ${ }^{88}$.

Poco debieron de afectar a tan halagüeñas circunstancias dos hechos ya señalados, que podrían haber jugado en su contra. Las voluminosas e imprescindibles importaciones no competían, sino que eran complemen.

español de maderas] en conjunto, sino considerando separadamente las distintas regiones de que acabamos de ocuparnos» [«Sección mercantil» (1902), p. 432].

${ }^{k 7}$ GEHR (1983), p. 243.

${ }^{\mathrm{x} K}$ Paris (1943), pp. 60 y 62. Los precios relativos favorables a la madera tenían dos efectos aparentemente contradictorios. Por una parte, se estimulaba a los propietarios forestales y a los industriales para que aumentaran su producción de madera y, por otra, se incentivaba la sustitución de la madera por el hierro (o el cemento). Pero estas dos tendencias no eran excluyentes, ya que la época se caracterizaba por un rápida diversificación de la oferta de productos industriales derivados de la madera, con lo cual había campo sobrado para la expansión de la madera y del hierro (o del cemento); y, asimismo, porque España era un país donde una porción sustancial de su consumo tenía que satisfacerse con importaciones, y éstas eran objeto potencial de sustitución por la producción interior. 
tarias de la producción nacional, que, en último término, podía seguir creciendo con el aliciente de atender las necesidades que se cubrían con maderas del extranjero. De forma análoga, la fragmentación de los mercados españoles debió de entorpecer la comercialización de las maderas, pero proporcionaría, asimismo, rentas extraordinarias para algunos de los participantes mejor situados en el negocio, que pudieron estimular o fortalecer la tendencia al alza (ya muy firme) de nuestra producción de maderas.

Todo parece indicar que el primer tercio del siglo xx y, probablemente, también la segunda mitad del siglo XIX fueron un período muy propicio para la producción de madera en España. Y la mejor prueba de ello es la armónica convivencia que existía entre una producción forestal en alza, una rápida difusión de la industria de primera transformación (incluida la celulósica) y unas importaciones crecientes poco protegidas. $\mathrm{Y}$ en este contexto debe entenderse la intervención del Estado, tanto las actuaciones lievadas a cabo en los montes públicos que administraba, como las medidas adoptadas para todos los predios forestales, especialmente las relativas a las repoblaciones ${ }^{89}$.

Pero después de la contienda civil, como sucedió con tantos otros asuntos, se modificó profundamente el escenario macroeconómico en que se desenvolvía la economía de la madera. El Cuadro 10 no deja duda al respecto: en los años del llamado «primer franquismo» se produjo, al mismo tiempo, una intensa subida del consumo y una drástica disminución de las importaciones. La situación era muy distinta a la del primer tercio del siglo. ¿Qué había pasado? He aquí la respuesta de los autores del estudio de Cultura Hispánica. La cita es larga, pero no tiene desperdicio:

«Antes de 1931, las cuantiosas importaciones de madera, aunque tal vez excesivas - ya que impedian o convertían en ruinosos algunos aprovechamientos nacionales-- contribuyeron de una manera indudable y notoria no sólo a la conservación de nuestro exiguo vuelo forestal, sino a su incremento, contrarrestado, en parte, por talas motivadas por roturaciones arbitrarias para dedicar las tierras al cultivo de cereal y, en menor escala, por los apetitos del ganadero para aumentar la superficie de pastos a costa del bosque [...]

${ }^{89}$ Las repoblaciones son, en efecto, uno de los factores que más directamente intervinieron en la marcha de la producción de madera, sobre todo desde el comienzo de la época franqujsta. Esta vinculación entre repoblación forestal e incremento de la producción maderera salta a la vista en el documento fundacional del Patrimonio Forestal de España, antecedente del Patrimonio Forestal del Estado [«Dictamen...» (1935)] [objeto de una severa critica en Arbós (1935), pp. 299-318]; y también en Ximénez (1932), en Aguado y Foxá (1949) y en algunas investigaciones recientes, como la de Groome (1990) y la de Aedo, Diego, García Codrón y Moreno (1991). 
La gran disminución de las importaciones de madera y de pastas celulósicas después del Alzamiento cambió totalmente el mercado interior de los aprovechamientos de madera, provocando un notable aumento de las cortas en nuestros montes [...] dicho aumento es excesivo y [...] por consiguiente, las cortas anuales son superiores a la posibilidad técnica o renta en madera, lo que presupone realizaciones del capital vuelo, cuya cuantía es imposible de precisar, aunque se intuya que es de importancia [...] Últimamente, el Servicio de la Madera [ha calculado que] las cantidades de madera cortadas indebidamente en los años 1940 a 1956 (16 millones de $\mathrm{m}^{3}$ ) [equivalen a] un millón de $\mathrm{m}^{3}$ por año» 90 .

De modo que la autosuficiencia maderera, posterior a la guerra civil, fue un fenómeno engañoso, resultado de una imprudente y descapitalizadora sobreexplotación del bosque, imposible de mantener por mucho tiempo, y de la cual se desprendía la inminente necesidad de las repoblaciones, que por enésima vez salen a relucir al tratar de la madera.

\section{LAS «FÁBRICAS DE ASERRAR MADERA»}

Así, «fábricas de aserrar madera», es como llama la Estadística de la Contribución Industrial y de Comercio a los aserraderos, la más genuina industria de primera transformación de la madera y la única de la que voy a ocuparme, por tratarse de la actividad más vinculada a la producción forestal.

Como fuente básica para el análisis, voy a utilizar la mencionada Estadística, cuyas ventajas e inconvenientes se han puesto de manifiesto en otro lugar, ya citado en el primer epígrafe ${ }^{91}$. No obstante, en el caso concreto de la industria del aserrío, deben añadirse dos importantes advertencias, una negativa y otra positiva. La negativa es que la ausencia de Navarra y del País Vasco (por tener un régimen fiscal especial) supone un grave defecto, puesto que los aserraderos de estas cuatro provincias (sobre todo, de Navarra y Vizcaya) debian de tener una notable importancia dentro del conjunto de España, como se desprende de las cifras de la década de 1960 , que luego se comentarán. Y la positiva es que tiene sentido comparar los datos de 1930 con los de años anteriores, porque, al tratarse de «fábricas» de muy reducida dimensión, serían muy pocas las que pasaran a tributar por conceptos ajenos a la contribución industrial.

${ }^{91}$ Robert (dir.) (1957), pp. 78-80. A estas cortas excesivas ya se habían referido Aguado y Foxá (1949), p. 20.

${ }^{41}$ Con una finalidad semejante a la que ahora persigo, la Estadistica de la Contribución Industrial y de Comercio ya ha sido utilizada en Rico (1994). 
Las «fábricas de aserrar madera» tienen muchos rasgos en común con la industria preparadora del corcho. Ambas son auxiliares e independientes de la industria transformadora respectiva, considerada ésta en un sentido estricto. Auxiliares, porque de ellas se obtienen productos semielaborados, que deben pasar por otros procesos de fabricación antes de ser destinados al consumo; e independientes, porque es rara la integración vertical de estas dos actividades transformadoras. Y ambas, aserrio y preparación del corcho, suelen estar situadas cerca de la materia prima, para reducir los costes de transporte, y tienen procesos productivos con un uso relativamente bajo del factor capital, pero donde resulta imprescindible el empleo de una mano de obra cualificada por la experiencia adquirida en el ejercicio de la profesión.

El Cuadro 11 ofrece una visión general de la evolución de las «fábricas de aserrar madera» en toda España desde mediados del siglo XIX hasta 1930 , y lo primero a destacar, mirando el número de contribuyentes y el importe de las cuotas (aun admitiendo que las cifras de los primeros años de la serie sean muy defectuosas), es el intenso y sostenido crecimiento que registró esta actividad. Y, simultáneamente al aumento de los aserraderos, se produjo una mejora del equipamiento, al adoptarse de forma progresiva y generalizada la sierra de cinta, como lo ponen de manifiesto

\section{CUADRO 11}

Algunos indicadores de las «fábricas de aserrar madera» en España, 1879-1930

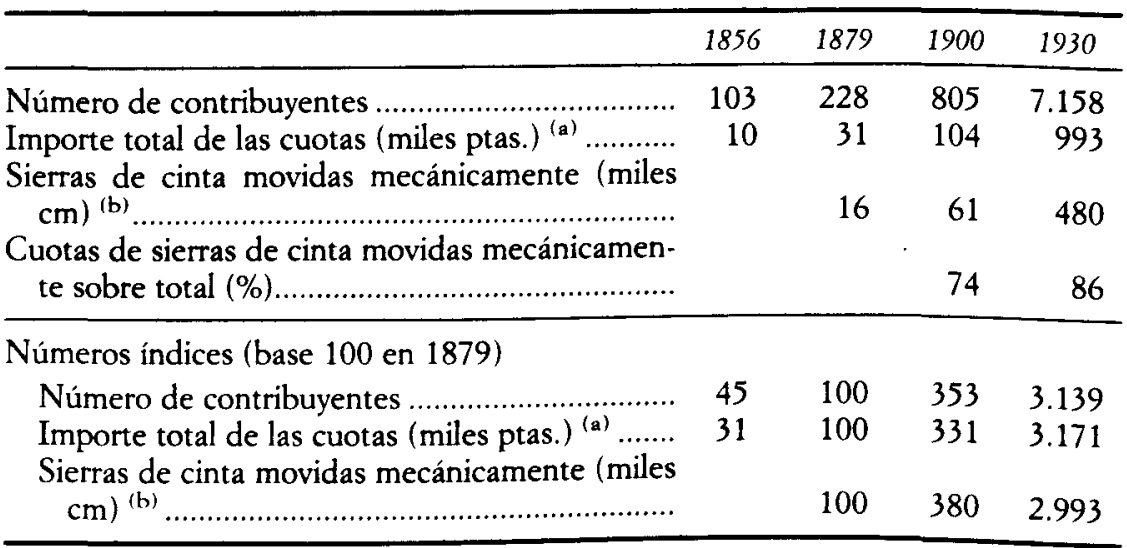

\footnotetext{
(a) Pesetas corrientes en 1856, 1879 y 1900, y pesetas de 1913 en 1930.

(b) Suma de $\mathrm{cm}$ de diámetro de las poleas.

Fuente: Estadistica de la Contribución Industrial y de Comercio.
} 
los correspondientes números índices y el porcentaje que representaban las cuotas de estas sierras sobre el total de lo recaudado.

El Cuadro 12 deja ver con claridad que los aserraderos, representados por el número de contribuyentes y por el importe de las cuotas, estaban muy concentrados en unas pocas provincias, entre las cuales destacaba un primer grupo compuesto por tres muy productoras de materia prima (Burgos, Soria y Pontevedra) y por los cuatro centros de consumo más importantes del momento (Barcelona, Madrid, Valencia y Sevilla) ${ }^{92}$. Pero asimismo se observa que esta concentración se redujo mucho con el paso del tiempo y que existieron evoluciones muy diferentes entre unas y otras provincias.

Cabe hacer cuatro grupos con las provincias españolas. El primero, el de aquellas que siempre tuvieron un elevado número de aserraderos, en el cual estarían Barcelona (la primera de la lista, sin duda alguna), Madrid, Pontevedra y, tal vez, Sevilla. El segundo sería el de las provincias que, teniendo tradición de aserrío, perdieron muy deprisa gran parte de la importancia relativa que las caracterizó en otras épocas, como sucedió en Burgos y Soria ${ }^{93}$. Un tercer grupo, de los nuevos aserraderos (valga la expresión), representado por Valencia, donde, partiendo de niveles muy bajos, se registra un rapidísimo crecimiento ${ }^{94}$. Y un cuarto grupo, muy amplio y heterogéneo, formado por las provincias que percibieron los efectos de la dispersión por toda España de las «fábricas de aserrar madera», principal causa de la atenuación de la concentración espacial aludida.

No es fácil identificar las causas de todos estos cambios de localización, siendo tan rudimentarios todavía los conocimientos que tenemos sobre la economía de la madera, aunque una de las tendencias de fondo tal vez fuera la que actuaba a favor de incrementar el número y la capacidad de los aserraderos próximos a los centros de consumo, en detrimento de los situados en las zonas de producción. Esto, al menos, cuadra con la citada dispersión y con la evolución del número de contribuyentes de las siete primeras provincias del Cuadro 12, cuando se distingue entre productoras (Burgos, Pontevedra y Soria) y consumidoras (Barcelona, Madrid,

${ }^{92}$ Recuérdese que Navarra y las provincias vascongadas no figuran en la Estadística de la Contribución Industrial y de Comercio.

${ }^{93}$ Se podría añadir a este grupo la provincia de Málaga.

"4 «Al calor de la exportación frutera, los embalajes se convirtieron en la gran especialidad de la carpintería del País Valenciano [...] De los embalajes, la industria valenciana de la madera derivó hacia otros artículos más sofisticados y más valiosos, tales como los juguetes y, sobre todo, los muebles» [Nadal (1990), p. 307]. El caso de Oviedo debe de ser muy distinto al de Valencia, pero, por sus cifras, también podría incluirse entre los nuevos centros de aserrío. 


\section{CUADRO 12}

Distribución espacial de las «fábricas de aserrar madera», 1856-1930 (porcentajes sobre el total de cada año de las provincias con mayor número de contribuyentes

$y$ con mayor cuota)

\begin{tabular}{|c|c|c|c|c|c|c|c|c|}
\hline & \multicolumn{4}{|c|}{ Número total de contribuyentes } & \multicolumn{4}{|c|}{ Importe total de las cuotas } \\
\hline & 1856 & 1879 & 1900 & 1930 & 1856 & 1879 & 1900 & 1930 \\
\hline Barcelona.. & 16,5 & 26,3 & 19,9 & 15,4 & 16,5 & 34,1 & 15,1 & 13,9 \\
\hline Burgos... & 21,4 & 7,5 & 3,9 & 2,1 & 21,4 & 2,0 & 2,7 & 1,8 \\
\hline Madrid. & 6,8 & 3,1 & 2,9 & 6,6 & 6,8 & 3,8 & 7,0 & 4,8 \\
\hline Pontevedra........ & 7,8 & 4,4 & 3,7 & 4,0 & 7,8 & 3,2 & 6,4 & 5,5 \\
\hline Sevilla ................. & 4,9 & 4,4 & 3,2 & 3,1 & 4,9 & 5,0 & 4,6 & 3,1 \\
\hline Soria .................... & 11,7 & 16,7 & 3,6 & 0,9 & 11,7 & 6,1 & 1,5 & 1,2 \\
\hline Valencia... & 1,9 & 7,5 & 12,0 & 7,4 & 1,9 & 8,6 & 18,2 & 11,4 \\
\hline Alicante .............. & & 1,8 & 2,9 & 1,6 & & 2,1 & 6,3 & 2,3 \\
\hline Baleares.............. & 1,0 & 2,6 & 3,5 & 2,5 & 1,0 & 1,2 & 3,6 & 2,8 \\
\hline Cádiz ................ & 3,9 & 1,8 & 1,7 & 1,9 & 3,9 & 2,4 & 3,3 & 1,6 \\
\hline Castellón ............ & 1,9 & 0,9 & 0,6 & 1,7 & 1,9 & 0,3 & 0,3 & 3,2 \\
\hline Coruña ............... & & 1,3 & 3,7 & 3,2 & & 2,7 & 3,2 & 5,2 \\
\hline Gerona ............... & & 0,9 & 5,2 & 2,9 & & 1,7 & 4,0 & 2,1 \\
\hline Huesca ............... & 3,9 & 2,2 & 0,6 & 1,9 & 3,9 & 0,7 & 0,1 & 2,7 \\
\hline Lérida................. & 6,8 & 0,4 & 3,2 & 1,6 & 6,8 & 1,3 & 2,0 & 1,6 \\
\hline Málaga................. & 3,9 & 2,2 & 3,0 & 1,1 & 3,9 & 7,1 & 2,1 & 0,9 \\
\hline Oviedo ............... & & 1,3 & 6,5 & 4,4 & & 1,0 & 4,9 & 2,7 \\
\hline Santander........... & 4,9 & 0,9 & 2,5 & 4,1 & 4,9 & 2,9 & 1,6 & 1,6 \\
\hline Zaragoza ........... & 1,9 & & 3,0 & 1,7 & 1,9 & & 1,7 & 1,4 \\
\hline Suma ${ }^{(a)} \ldots \ldots \ldots \ldots$ & 71,0 & 69,9 & 49,2 & 39,5 & 71,0 & 62,8 & 55,5 & 41,7 \\
\hline Suma ${ }^{(b)} \ldots \ldots \ldots \ldots$ & 28,2 & 16,3 & 36,4 & 28,6 & 28,2 & 23,4 & 33,1 & 28,1 \\
\hline Suma ${ }^{(c)}$. & 99,2 & 86,2 & 85,6 & 68,1 & 99,2 & 86,2 & 88,6 & 69,8 \\
\hline España ............... & 100,0 & 100,0 & 100,0 & 100,0 & 100,0 & 100,0 & 100,0 & 100,0 \\
\hline
\end{tabular}

(a) Suma del grupo de las primeras siete provincias.

(b) Suma del grupo de las segundas doce provincias.

(c) Suma de las diecinueve provincias consideradas, que son todas las que alcanzan el 3 o más por 100 en número de contribuyentes o en el importe de las cuotas en alguno(s) de los años estudiados.

FuENTE: Estadística de la Contribución Industrial y de Comercio. 
Sevilla y Valencia), ya que las primeras tienen el 29 por 100 de los contribuyentes españoles en 1879, pero sólo el 7 por 100 en 1930, mientras que las segundas, entre las mismas fechas, sólo bajan del 41 al 33 por 100.

En el caso de las «fábricas de aserrar madera», el elemento técnico determinado por la legislación fiscal para definir la capacidad de cada establecimiento ( $y$, en consecuencia, la cuota de cada contribuyente) era el tipo de sierra empleado, que, por la extrema sencillez del capital instalado en las susodichas fábricas, puede considerarse un fiel reflejo del nivel técnico de la industria en cuestión.

Durante el siglo XIX, se produjeron muy pocas mejoras en las herramientas del aserrado. Al respecto, Latham afirma, categórico: «La historia de la producción masiva de madera de construcción es, en la práctica, la historia de la invención y difusión de la sierra de cinta» ${ }^{95}$. Y la sierra de cinta sólo estuvo en condiciones de ser empleada y difundida ( $y$, por consiguiente, de sustituir a las sierras alternativas) a finales del citado siglo $\mathrm{XIX}{ }^{96}$. La rapidez con que fue adoptada la sierra de cinta en el extranjero y en España pudo obedecer a tres motivos. Se trataba, en primer lugar, de una innovación que aportaba un notable incremento de la productividad del factor trabajo; en segundo lugar, de una máquina de fácil manejo e instalación; y, por último, de una inversión modesta.

No todas las sierras de cinta eran iguales. Con el paso del tiempo, se fueron incorporando mejoras y aumentaron los rendimientos, que también variaban según la fuerza motriz utilizada. En España, como ponía de manifiesto el Cuadro 11, se adoptó con prontitud la novedad de la sierra de cinta, que también se difundió con mucha rapidez. Y el Cuadro 13 se refiere, otra vez, al fenómeno de la concentración espacial de la industria, que fue debilitándose como efecto de la difusión de la misma. Sin embargo, parece que esta difusión de las «fábricas de aserrar madera» no trajo consigo más que una multiplicación del número de establecimientos (con rendimientos mejorados, eso sí, gracias a la sierra de cintas). Otros cambios, como la superación del minúsculo tamaño de las empresas, no se produjeron, a juzgar por la evolución de los centímetros de diámetro de las poleas de las sierras de cinta por contribuyente. Dado que el diámetro de la polea del rotor de una sierra de cinta de tamaño medio solía medir de 80 a 100 $\mathrm{cm}$., resulta que el aserradero tipo de 1900 (con $137 \mathrm{~cm}$. por contribuyente) tendría 1,5 sierras de cinta, y el de 1930 (con $89 \mathrm{~cm}$. por contribuyente)

\footnotetext{
95 Latham (1957), p. 214.

*6 Latham (1957), pp. 119-120 y 207-223.
} 


\section{CUADRO 13}

Sierras de cinta movidas mecánicamente

en las «fábricas de aserrar madera» en 1900 y 1930

(suma de cm de diámetro de las poleas)

(porcentajes sobre el total de cada año

de las provincias con mayor número de $\mathrm{cm}$ )

\begin{tabular}{|c|c|c|}
\hline Provincia & 1900 & 1930 \\
\hline Alicante .... & 7,1 & 2,3 \\
\hline 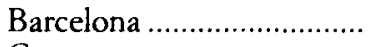 & 16,5 & 12,7 \\
\hline 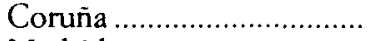 & 1,2 & 5,6 \\
\hline Madrid. & 6,2 & 5,6 \\
\hline Pontevedra ............................. & 5,4 & 6,4 \\
\hline 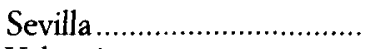 & 5,1 & 3,1 \\
\hline Valencia................................. & 24,2 & 9,1 \\
\hline Baleares................................. & 3,4 & 1,6 \\
\hline 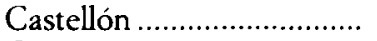 & 0,3 & 3,3 \\
\hline 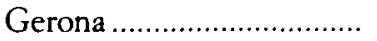 & 4,0 & 1,9 \\
\hline Murcia ................................ & 3,3 & 2,8 \\
\hline 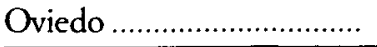 & 3,4 & 1,7 \\
\hline Suma ${ }^{\text {(a). }}$. & 65,7 & 46,8 \\
\hline Suma ${ }^{\text {(b) }} \ldots \ldots \ldots \ldots \ldots \ldots \ldots \ldots \ldots$ & 80,1 & 58,1 \\
\hline 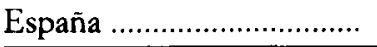 & 100,0 & 100,0 \\
\hline
\end{tabular}

(a) Suma del grupo de las primeras siete provincias.

(b) Suma de las doce provincias consideradas, que son todas las que alcanzan el 3 o más por 100 en alguno(s) de los años estudiados.

FUENTE: Estadistica de la Contribución Industrial y de Comercio.

sólo 1 sierra ${ }^{97}$. Es decir, que la difusión del aserrio, en vez de superar, acentuó la dimensión liliputiense de las empresas del ramo.

Es difícil interpretar la simultaneidad de una sucesión acumulativa de cambios (multiplicación y diseminación de los establecimientos, aproximación a los centros de consumo, mejoras de los rendimientos por la adopción generalizada de la sierra de cintas) con la persistencia de arcaicas y minúsculas estructuras empresariales, incapaces de aprovechar cualquier economía de escala.

${ }^{97} \mathrm{La}$ fuente de estas cifras es la Estadística de la Contribución Industrial y de Comercio. 
Parece que los expertos de la época eran conscientes de las modificaciones que se estaban produciendo en las «fábricas de aserrar madera» ${ }^{48}$. Y es muy probable que la demanda de madera procedente del ferrocarril (en particular, por las condiciones exigidas a las traviesas) contribuyera a la mejora de los aserraderos ${ }^{99}$. Pero también debieron de actuar (y con más fuerza, seguramente) otros factores de demanda, como las crecientes necesidades de embalajes, de madera para mina, de algunos elementos de la construcción y de pasta de papel, donde se utilizaba una importante cantidad de la madera extraída de nuestros bosques. Y cabe, asimismo, suponer que la difusión y las transformaciones apuntadas fueron demasiado lejos, creando o aumentando un exceso de capacidad en una industria con muy pocas barreras de entrada y donde tan frecuente debía de ser el trabajo estacional ${ }^{100}$. Todo lo cual venía a suponer un pesado lastre que dificultaba la aparición de grandes empresas capitalistas en esta rama de actividad.

Resulta ilustrativo, finalmente, comparar la situación de las «fábricas de aserrar» en 1930 con la de treinta años después, porque, como se puede apreciar en el Cuadro 14, algunas de las características comentadas se han mantenido y otras se han modificado ${ }^{101}$. Por ejemplo, continuó habiendo numerosas y minúsculas empresas. Los 7.000 contribuyentes de 1930 se

"* El siguiente texto, tomado de una publicación oficial, quizás fuera representativo de la opinión de los citados expertos: «En la industria maderera se van operando transformaciones, en armonía con las necesidades de cada época. Cuando los precios de las maderas eran menores, al propio tiempo que las cortas de los árboles, se efectuaban en el mismo monte el despiezo de cada tronco [...] En la actualidad, en las cortas maderables que las condiciones extrínsecas del predio lo permiten, las operaciones de la industria hachera se reducen al apeo del árbol, separación de la copa y ligero descortezamiento de los troncos [...] En tal estado [...] se transportan a las fábricas de aserrar y, prescindiendo casi en absoluto del marco usado en la localidad, se transforma en las piezas más solicitadas en el mercado por los consumidores; hasta los costeros, desperdicios, serrín, etc., todo es objeto de aplicación y ventam [Dirección General de Agricultura, Minas y Montes (1915), pp. XLVU-XL.JX].

${ }^{49}$ Gómez Mendoza (1989), pp. 109-113.

${ }^{10(1)}$ La autorizada opinión de Arbós sobre este particular no ofrece duda, cuando afirma, en 1935, que han sido muy «numerosas las [fábricas de aserrar] establecidas durante los periodos de guerra europea y el de post-guerra en todos los ámbitos de España [...] [y que es] excesiva su capacidad de producción en relación con lo que el mercado español puede absorber de la misma, especialmente en la región de Levante» [Arbós (1935), p. 181].

101 La fuente utilizada en el Cuadro 14 es la Estadistica de las Industrias de Primera Transformación de la Madera, cuya publicación comenzó en 1960. Por encargo del Ministerio de Industria, se elaboraba por el sindicato vertical del ramo, mediante encuesta directa a todos los establecimientos, y parece que sus resultados eran bastante fieles a la realidad. Pero hasta 1964 no se proporcionaron datos provinciales suficientemente desagregados, motivo por el que se utiliza este año para el cuadro citado. 


\section{CUADRO 14}

Algunos indicadores de las industrias de primera transformación de la madera en España en 1964 (provincias donde tienen más importancia las citadas industrias)

\begin{tabular}{|c|c|c|c|c|}
\hline Provincia & (a) & (b) & (c) & (d) \\
\hline Coruña ... & 14,3 & 12,2 & 6,6 & 9,7 \\
\hline Pontevedra... & 6,7 & 8,8 & 8,6 & 5,6 \\
\hline Navarra ......... & 6,6 & 3,6 & 9,7 & 4,9 \\
\hline 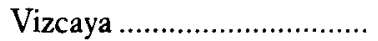 & 5,9 & 4,8 & 6,3 & 4,7 \\
\hline 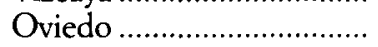 & 5,8 & 5,3 & 6,5 & 8,4 \\
\hline Barcelona ............................... & 5,6 & 8,3 & 5,0 & 2,4 \\
\hline 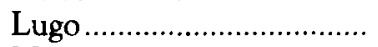 & 4,5 & 2,9 & 3,9 & 4,5 \\
\hline 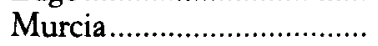 & 3,7 & 3,1 & 12,0 & 0,9 \\
\hline 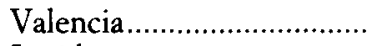 & 3,3 & 4,9 & 8,5 & 2,6 \\
\hline 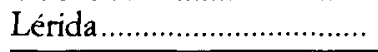 & 3,1 & 2,5 & 12,9 & 3,1 \\
\hline Gerona.. & 2,7 & 3,4 & 6,1 & 1,4 \\
\hline 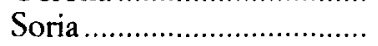 & 2,5 & 2,5 & 9,9 & 3,9 \\
\hline  & 2,4 & 2,4 & 7,2 & 2,4 \\
\hline Orense ... & 2,2 & 2,2 & 3,6 & 1,2 \\
\hline Segovia ..................... & 2,1 & 1,7 & 8,4 & 2,5 \\
\hline 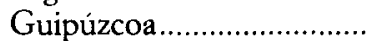 & 1,9 & 1,8 & 4,2 & 1,3 \\
\hline  & 1,8 & 1,3 & 13,1 & 5,6 \\
\hline 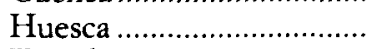 & 1,8 & 1,5 & 9,3 & 2,1 \\
\hline 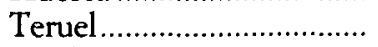 & 1,7 & 1,4 & 6,5 & 4,1 \\
\hline 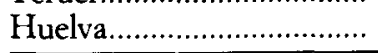 & 1,5 & 0,9 & 4,8 & 2,7 \\
\hline Suma ${ }^{(a)}$. & 59,5 & 56,4 & 7,4 & 46,8 \\
\hline Suma ${ }^{(b)}$. & 20,6 & 19,1 & 7,2 & 27,2 \\
\hline Suma ${ }^{(c)}$.. & 80,1 & 75,5 & 7,4 & 74,0 \\
\hline 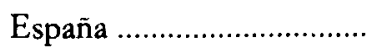 & 100,0 & 100,0 & 5,8 & 100,0 \\
\hline
\end{tabular}

(a) Porcentaje sobre la cantidad total de madera elaborada en España.

(b) Porcentaje sobre el número de empleados de España.

(c) Número medio de empleados por serrería.

(d) Porcentaje sobre la producción de madera de los montes de España en 1964-1966.

(a) Suma del grupo de las primeras diez provincias. La cifra de (c) es la media ponderada con las correspondientes cantidades de (b).

(b) Suma del grupo de las segundas diez provincias. La cifra de (c) es la media ponderada con las correspondientes cantidades de (b).

(c) Suma del grupo de las veinte provincias consideradas. La cifra de (c) es la media ponderada con las correspondientes cantidades de (b).

Fuentes: Dirección General de Montes, Caza y Pesca Fluvial (1965), pp. 17-18 y 29; GEHR (1996b), p. 197. 
redujeron, es verdad, a poco más de 5.000 establecimientos en 1964, pero el promedio de 6 trabajadores por fábrica es un buen reflejo de que seguía vigente la norma de la dimensión ínfima. $\mathrm{Y}$, asimismo, se mantuvo vigente el binomio concentración-difusión, aunque parece que el primer término ha aumentado en detrimento del segundo, tal vez por los cambios que se observan en el grupo de las 10 primeras provincias. Navarra y Vizcaya aparecen ( $\mathrm{y}$ también Guipúzcoa) en el grupo de las 10 segundas, porque antes no eran tenidas en cuenta en la Estadística de la Contribución Industrial $y$ de Comercio. Pero más llamativa es la desaparición de Madrid y Sevilla y el asentamiento de la especialización maderera del Cantábrico (con Galicia a la cabeza), cuya explicación se me escapa, como tantas otras cuestiones relacionadas con la economía de la madera.

\section{CONCLUSIONES}

Enumeraré de forma muy sucinta las principales conclusiones del presente trabajo. El período estudiado podría calificarse de transición en la historia de las aplicaciones de la madera, puesto que se fue debilitando el predominio de la madera maciza, al tiempo que se forjaba el nuevo predominio de la madera triturada o desintegrada, lo cual trajo consigo profundas modificaciones en los sistemas forestales de explotación y en las técnicas de transformación industrial.

En el contexto internacional, las grandes potencias madereras fueron, en Europa, los países del Báltico (con Suecia en primera fila, seguida de Finlandia) y, en la otra orilla del Atlántico, Estados Unidos y Canadá. Pero esta situación se vio trastocada desde finales del siglo XIX por la creciente participación de Rusia, hasta la primera guerra mundial, y de la Unión Soviética, desde la década de 1920.

La madera siempre estuvo, durante el período estudiado (hasta la guerra civil), entre los principales artículos de nuestras importaciones. Durante el primer tercio del siglo $\mathrm{xx}$, dichas importaciones representaban la mitad del consumo interno de maderas y eran de todo punto imprescindibles, pero, dada la composición de las mismas (madera de construcción, en su mayor parte), no entraban en competencia con la producción interior, sino que le servían de complemento.

La producción de madera en España registró un crecimiento intenso y sostenido, derivado de un alza en los rendimientos más que de la ampliación de la superficie aprovechada, y ello dentro de una tendencia hacia 
la «maderización» de la producción forestal. Además, esta expansión maderera tuvo lugar tanto en los montes públicos como en los de particulares, aunque la proporción de unos y otros variaba mucho entre las provincias.

El crecimiento de la población (sobre todo, en las grandes urbes) y de la renta disponible debieron de estimular la demanda interior, que aumentó con rapidez, absorbiendo cada vez mayores cantidades per cápita de madera española y extranjera.

Las «fábricas de aserrar madera» experimentaron, en España, una rapidísima difusión y adoptaron de forma generalizada la sierra de cinta, que era la innovación técnica del momento, pero persistió la extrema pequeñez de los establecimientos.

La madera formaba parte de la economía de todas las provincias españolas, pero con un peso absoluto y relativo muy desigual. En la época analizada, las actividades madereras de todo tipo estaban muy concentradas en el cuadrante noroccidental de la Península y en algunos grandes centros de consumo, entre los cuales destacaban Barcelona, Madrid, Valencia y Sevilla.

La importancia económica de la madera no se corresponde con la escasísima atención que le han prestado, hasta ahora, los investigadores. Es preciso conocer más y mejor la historia económica de la madera, si se quieren entender los límites y posibilidades (pecuniarios y ambientales) de los bosques, en general, y de los bosques españoles, en particular. En esta tarea, y teniendo en cuenta este primer esbozo, considero que, en los próximos años, los investigadores españoles deberíamos dar preferencia a los siguientes temas: al período comprendido entre 1936 y la actualidad; a la comercialización de la madera, en los mercados internos y en los internacionales, prestando atención especial a determinadas coyunturas; a la repoblación forestal, pero examinándola a la luz de la economía de la madera y de sus industrias derivadas; y, por último, al papel representado por la madera en la industria de la construcción.

\section{APÉNDICE}

\section{Una estimación de la producción de madera en España en 1900-1904 y 1931-1935}

El método que va a seguirse en la estimación de la producción de madera en España de los quinquenios 1900-1904 y 1931-1935 no es otro que aplicar, con ligeras modificaciones, el procedimiento seguido, para 1951-1955, en la publi- 
cación, ya citada, del Instituto de Cultura Hispánica, y que consistía en una estimación indirecta de la producción por medio del consumo, según la igualdad

Producción estimada $=$ Consumo estimado - Importaciones + Exportaciones ${ }^{102}$

Los supuestos y consideraciones en que se basa la estimación realizada son los siguientes:

1. La elección de los quinquenios de 1900-1904 y 1931-1935 está condicionada por el período para el que se cuenta con datos de la producción de los montes de utilidad pública, que, como se verá, serán utilizados para constrastar el grado de veracidad de las cifras estimadas. Me parecieron suficientes dos quinquenios para tener una idea de la tendencia de la producción durante tres décadas, ya que, de haber establecido una fecha intermedia entre los dos quinquenios elegidos, habría sido difícil evitar las profundas alteraciones que ocasionó la Primera Guerra Mundial en el comercio exterior de madera.

2. El consumo se ha dividido, como se hace en Robert (dir.) (1957), en ocho partidas (minas de carbón, construcción, envases y embalajes, traviesas para el ferrocarril, tableros, pastas celulósicas, postes y usos diversos), calculándose el montante de cada una de ellas, para llegar en todos los casos a las cifras de rollo con corteza (expresadas en $\mathrm{m}^{3}$ ), como sigue:

\subsection{Madera para minas de carbón:}

Se ha multiplicado la producción media agregada de carbón de 1900-1904 y de 1931-1935 por el coeficiente de $0,07 \mathrm{~m}^{3}$ de madera por Tm. de carbón extraído ${ }^{103}$. Al tener en cuenta las minas carboníferas, exclusivamente, se está infravalorando esta partida en una proporción desconocida, pero que sería mayor en 1900-1904 que en 1931-1935, ya que en estos últimos años la actividad minera había decaído mucho con relación a la de principios del siglo ${ }^{104}$.

\subsection{Madera para la construcción:}

Se ha multiplicado el número de habitantes de 1902 y de 1933 por el coeficiente de $0,06 \mathrm{~m}^{3}$ de madera ${ }^{105}$.

${ }_{102}$ Robert (dir.) (1957), pp. 39-70. El método de este trabajo es mucho más riguroso que los empleados en Lleó (1929), pp. 173-174, y en Aguado y Foxá (1949), pp. 17-31. ${ }^{103}$ La producción de carbón se ha tomado de Coll y Sudrià (1987), p. 329; y el coeficiente de Robert (dir.) (1957), p. 41.

${ }^{104}$ Es obvio que todas las galerías de una mina necesitan ser entibadas, cualquiera que sea el objeto de su explotación, pero es muy arriesgado asignar un coeficiente a la producción de diversos minerales sin tener referencias en qué apoyarse, pues de los relativos al carbón se desprende una ostensible variación entre los diversos coeficientes, ya que el de la hulla $\left(0,078 \mathrm{~m}^{3} / \mathrm{Tm}\right.$.) duplica al de la antracita $\left(0,038 \mathrm{~m}^{3} / \mathrm{Tm}\right.$.) [Brown (1937), pp. 89 y 95; Robert (dir.) (1957), pp. 41-42].

1115 La población se ha tomado de Nicolau (1989), pp. 70-71; y el coeficiente de Robert (dir.) (1957), p. 62 (adviértase que en la última frase de la p. 61 debe de haber un error tipográfico en «se acepta el coeficiente de $0,05 \mathrm{~m}^{3}$ en rollo con corteza por habitante y 
La cifra de 1931-1935 es la que figura en Robert (dir.) (1957) para 1933-1935, y la de 1900-1904 está calculada suponiendo que en esos años sólo se consumió pasta de papel y que ésta se importó en su totalidad. Ahora bien, de toda la pasta consumida, sólo una parte procedía de la madera ${ }^{110}$, y por ello en Robert (dir.) (1957) los $254.000 \mathrm{Tm}$. de toda clase de pasta sólo equivalen a 260.000 $\mathrm{m}^{3}$ de rollo con corteza, o sea, simplificando: $1 \mathrm{~m}^{3}$ de rollo con corteza por cada Tm. de toda clase de pasta. Y esta equivalencia es la que aplicaré a 1931-1935 y a 1900-1904, a sabiendas de que en este último quinquenio se estará infravalorando el consumo de madera por no haberse contabilizado más que la pasta importada.

\subsection{Madera para postes:}

Al no disponer de la información necesaria para realizar la estimación correspondiente, supondré que esta partida guarda en 1900-1904 y en 1931-1935 la misma proporción respecto al consumo total que en 1951-1955, esto es, el 0,7 por 100 .

\subsection{Madera para usos diversos:}

Como en el caso anterior (y por tratarse, además, de una partida complejísima, con numerosas subpartidas, de muy difícil cuantificación), mantendré en 1900-1904 y en 1931-1935 la misma proporción respecto al consumo total que en 1951-1955, esto es, el 2,4 por 100 .

3. Las cantidades importadas y exportadas de madera, que figuran en la fuente en $\mathrm{m}^{3}$ y $\mathrm{Qm}$., se han convertido en $\mathrm{m}^{3}$ de rollo con corteza, mediante las siguientes equivalencias y suponiendo que la madera sin elaborar es rollo sin corteza:

$1 \mathrm{~m}^{3}$ de madera sin elaborar $=1,25 \mathrm{~m}^{3}$ de rollo con corteza ${ }^{111}$

$1 \mathrm{~m}^{3}$ de madera elaborada $=2,05 \mathrm{~m}^{3}$ de rollo con corteza ${ }^{112}$

$1 \mathrm{Tm}$. de madera (elaborada o no) $=1,54 \mathrm{~m}^{3}$ de madera (elaborada o no) ${ }^{113}$

$1 \mathrm{Tm}$. de madera sin elaborar $=1,92 \mathrm{~m}^{3}$ de rollo con corteza

$1 \mathrm{Tm}$. de madera elaborada $=3,16 \mathrm{~m}^{3}$ de rollo con corteza

$1 \mathrm{Tm}$. de pasta $=6,25 \mathrm{~m}^{3}$ de rollo con corteza ${ }^{114}$.

${ }^{110}$ Quizás, la mayor parte de la pasta importada fuese pasta de madera, pero no pasaba lo mismo con la de producción nacional, que sólo procedía de la madera en un 20 o 25 por 100 en 1951-1955 [Gutiérrez i Poch (1994); Gutiérrez i Poch (1996); Robert (dir.) (1957), p. 109].

111 Robert (dir.) (1957), p. 64.

${ }_{112}$ Es el coeficiente que resulta del consumo total de envases y embalajes [Robert (dir.) (1957), p. 50].

113 Robert (dir.) (1957), p. 64.

114 Es el coeficiente que se utiliza en Robert (dir.) (1957), p. 53. Quizás sea demasiado alto, porque es el que se aplica a la pasta al bisulfito. 


\section{CUADRO A}

Estimación del consumo de madera en España, 1900-1955

(promedios quinquenales en miles de $\mathrm{m}^{3}$ de rollo con corteza)

\begin{tabular}{|c|c|c|c|}
\hline$A \bar{n} o s$ & $1900-1904$ & 1931.1935 & $1951-1955$ \\
\hline Minas de carbón....................... & 192 & 488 & 1.159 \\
\hline Envases y embalajes .............. & 419 & 1.256 & 1.256 \\
\hline 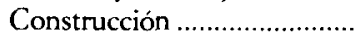 & 1.127 & 1.447 & 1.811 \\
\hline Traviesas de ferrocarril.......... & 83 & 30 & 368 \\
\hline 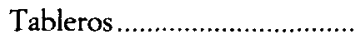 & - & 151 & 151 \\
\hline 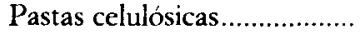 & 27 & 213 & 260 \\
\hline Postes & 13 & 26 & 38 \\
\hline Usos diversos........................... & 46 & 89 & 121 \\
\hline Total & 1.907 & 3.700 & 5.164 \\
\hline
\end{tabular}

FulNTE: Supuesto 2 de este apéndice; Robert (dir.) (1958), p. 70.

\section{CUADRO B}

Cantidades de las importaciones y exportaciones españolas de madera sin elaborar y elaborada y de pasta de papel, según las facilita la fuente y bomogeneizadas según el Supuesto 3 (miles de $m^{3}$ y miles de $T m$ )

\begin{tabular}{|c|c|c|c|c|c|}
\hline & \multicolumn{2}{|c|}{ M. sin elaborar } & \multirow{2}{*}{ M. elabor. } & \multirow{2}{*}{$\begin{array}{c}\text { Pasta } \\
T m \\
\end{array}$} & \multirow{2}{*}{$\frac{\text { Total }}{m^{3}}$} \\
\hline & $m^{3}$ & $T m$ & & & \\
\hline \multicolumn{6}{|l|}{ Importaciones ${ }^{(a)}$} \\
\hline $1900-1904 \ldots \ldots \ldots \ldots \ldots \ldots$ & 587 & 3 & 42 & 27 & \\
\hline 1931-1935 ........................ & 546 & 60 & 17 & 125 & \\
\hline \multicolumn{6}{|l|}{ Exportaciones ${ }^{(a)}$} \\
\hline 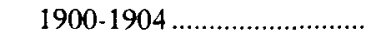 & - & 21 & 26 & 一 & \\
\hline \multirow[t]{2}{*}{ 1931-1935 } & 1 & 2 & 31 & - & \\
\hline & $m^{3}$ & $m^{3}$ & $m^{3}$ & $m^{3}$ & \\
\hline \multicolumn{6}{|l|}{ Importaciones ${ }^{(b)}$} \\
\hline $1900-1904 \ldots \ldots \ldots \ldots \ldots$ & 734 & 6 & 133 & 169 & 1.042 \\
\hline $1931-1935 \ldots \ldots \ldots \ldots \ldots \ldots \ldots \ldots$ & 683 & 115 & 54 & 781 & 1.633 \\
\hline \multicolumn{6}{|l|}{ Exportaciones (b) } \\
\hline $1900-1904 \ldots \ldots \ldots \ldots \ldots \ldots \ldots \ldots$ & - & 40 & 82 & - & 122 \\
\hline $1931-1935 \ldots \ldots \ldots \ldots \ldots \ldots$ & 1 & 4 & 98 & - & 103 \\
\hline
\end{tabular}

(a) Unidades que facilita la fuente.

(h) Unidades homogeneizadas en miles de $\mathrm{m}^{3}$, según el Supuesto 3 de este apéndice.

FuENIEs: Estadisticas del Comercio Exterior de España (datos facilitados por Domingo Gallego y Vicente Pinilla); Gutiérrez (1994), p. 367; Supuesto 3 de este apéndice. 


\section{CUADRO C}

Estimación de la producción de madera en España, 1900-1955

(promedios quinquenales en miles de $\mathrm{m}^{3}$ de rollo con corteza)

\begin{tabular}{|c|c|c|c|}
\hline Años & $1900-1904$ & $1931-1935$ & $1951-1955$ \\
\hline 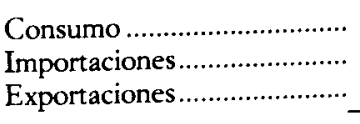 & $\begin{array}{r}1.907 \\
-1.042 \\
122 \\
\end{array}$ & $\begin{array}{r}3.700 \\
-1.633 \\
103 \\
\end{array}$ & $\begin{array}{r}5.164 \\
-286 \\
21 \\
\end{array}$ \\
\hline Producción estimada ............. & 987 & 2.170 & 4.899 \\
\hline
\end{tabular}

FulNTL: Cuadros A y B de este apéndice; Robert (dir.) (1957), p. 76.

\section{BIBLIOGRAFÍA}

Aedo, C.; Diego, C.; García Cordón, J. C., y Moreno, G. (1991): El bosque en Cantabria, 2." ed., Santander, Universidad de Cantabria y Asamblea Regional de Cantabria.

AGNOLETTI, M. (1995): «Evoluzione tecnica e funzione produttiva delle segherie idrauliche in Trentino fra xx e xx secolo», SM Annali di San Michele, 8, pp. 121-137.

- (1996): «Techniche di utilizzazione dei boschi di alto fusto dall'Unità d'Italia al secondo dopoguerra», en Innovazione e Sviluppo: Tecnologia ed Organizzazione fra Teoria Economica e Ricerca Storica (XVt-XX secolo). Atti del Convegno Quadriennale della Società Italiana degli Storici dell'Economia, Piacenza, 4-6 marzo 1993, Bologna, pp. 79-97.

- (1998): Segherie e foreste nel Trentino. Dal Medioevo ai giomi nostri, Trento, Museo degli Usi e Costumi della Gente Trentina.

- (1999): «Foreste e industria del legno dall'Unità d'Italia al ventennio fascista», Preactas. IX Congreso de Historia Agraria, San Sebastián, pp. 707-720.

Aguado Smolinski, J., y Foxá Torroba, J. de (1949): El abastecimiento de maderas $y$ la posibilidad de regularlo, Madrid, Ministerio de Agricultura.

Arvenainen, J. (1984): Suomen sabateo llisuuden bistoria, Helsinki. (La traducción al castellano del título sería La bistoria de la serrería en Finlandia.)

- (1985): «The Competitive Position of the Finnish Sawmill Industry in the 1920's and 1930's», Scandinavian Economic History Review.

- (1988a): «Britain as Buyer of Finnish Saw Timber, 1760-1860», en L. R. FISHER y otros, Shipping and Trade in the Northern Sea, 1600-1939.

- (1988b): «The Financing of Finnish Timber Industries, 1870-1939», en L. R FISHER y otros, Shipping and Trade in the Northern Sea, 1600-1939.

- (1996): «Man and the Forest. The North», en S. Cavaciocchi (ed.), L'uomo e la foresta, secc. XII-XVIII, Firenze, Le Monnier, pp. 225-252.

Aranda y Antón, G. de (1991): «La Marina Real en la selvicultura del siglo XviI», Revista Forestal Española, 1, pp. 21-26. 
- (1995): Los bosques flotantes. Historia de un roble del siglo XVIII, Madrid, Ministerio de Agricultura, Pesca y Alimentación.

ARAQUe Jimenez, E. (1997): Privatización y agresiones a los montes públicos jiennenses durante la segunda mitad del siglo XIX, Jaén, Diputación Provincial de Jaén.

Arbós Altafaja, J. (1935): Los problemas de la madera. Su importancia en España, cómo se ban tratado y sus relaciones con nuestro comercio exterior, proyectado convenio con Rusia, politica de contingentes y repoblación forestal, Barcelona.

BARO, F. (1914): «Los transportes forestales en España», Revista de Montes, pp. $722-727,754-759$ y $800-806$.

- (1920): «Los transportes forestales en España», Revista de Montes, pp. 306-345, 363-375 y 406-418 [publicado en E. ARAQUe JimÉnez (comp.) (1996): Escritos forestales sobre las sierras de Segura y Cazorla, Jaén, Diputación Provincial de Jaén, pp. 83-129].

Bjorkiund, J. (2000): «Exploiting the Last Phase of the North European Timber Frontier for the International Market 1890-1914: an Economic-Historical Approach», en M. AGNOLETTI y S. ANDERSON (eds.), Forest History: International Studies on Socio-economic and Forest Ecosystem Change, Oxon y New York, CABI e IUFRO, pp. 171-184.

Brown, N. C. (1937): Timber Products and Industries. The Harvesting, Conversion, and Marketing of Materials Other than Lumber, including the Principal Derivates and Extractives, New York, John Wiley and Sons.

ButToud, G. (1977): «Prix et marché du bois a la fin du XIXe siècle», Revue Forestière Française, SP, pp. 129-138.

CAMPO, E. del (1888): «Los precios de la madera y del hierro», Revista de Montes, pp. 553.559 .

Chabrol, P. (1962): «Les bois de marine dans l'économie forestière française (du traité des Pyrénés 1659 au lancement du paquebot "France" 1961)», Revue Forestière Française, pp. 277-290.

Chapon, P. (1961): «Contribution a l'étude des prix sur le marché français des sciages chênes (Recherches sur la période 1949-1957)», Annales de l'École Nationale des Eaux et Forêts, pp. 131-329.

CHEw, Sing C. (1992): Logs for capital. The timber industry and capitalist enterprise in the 19th Century, GreenWood Press.

Coll Martin, S., y Sudrià i Triay, C. (1987): El carbón en España, 1770-1961. Una bistoria económica, Madrid, Turner.

Collins, E. J. T. (1996): «The Wood-Fuel Economy of Eighteenth Century England», en S. Cavacioccin (ed.), L'uomo e la foresta, secc. XII-XVIII, Firenze, Le Monnier, pp. 1097-1121.

Cox, Thomas R. (1988): «The North American-Japanese Timber Trade: A Survey of its Social, Economic, and Environmental Impact», en J. F. RicharDS y R. P. TUCKER (eds.), World Deforestation in the Twentieth Century, Durham and London, Duke University Press, pp. 164-188.

Derry, T. K., y Williams, T. I. (1977): Historia de la tecnología, vol. 2, Desde 1750 basta 1900 (I), Madrid, Siglo XXI.

«Dictamen sobre la creación del Patrimonio Forestal de España» (1935): Montes y Ríos, pp. 82-97. 
Dirección General de Agricultura, Minas y Montes (1915): Estadística general de la producción de los montes de utilidad pública, correspondiente al año forestal de 1912-1913, Madrid.

Dirección General de Montes, Caza y Pesca Fluvial (1964): Estadística de las industrias de primera transformación de la madera. Información anual. Datos de 1963, Madrid.

- (1965): Estadística de las industrias de primera transformación de la madera. Información anual. Datos de 1964, Madrid.

EgGerT, U. (1883): «Die Bewegung der Holzpreise und Tagelohn-Sätze in den preussischen Staatsforsten von 1800 bis 1879», Zeitschrift des Königlichen Preussischen Statistischen Bureaus, XXIII, pp. 1-44.

Enciclopedia Universal Ilustrada Europeo-Americana (s. a.): Barcelona, Hijos de J. Espasa.

EQUIPO INVESTTGADOR (1996): «Principales fuentes utilizadas», en S. ZAPATA BlanCO (ed.), La industria de una región no industrializada: Extremadura, 1750-1990, Cáceres, Universidad de Extremadura, pp. 23-68.

EsPido Bello, M. ${ }^{\text {a }}$ C. (1995): As relacións económicas bispano-portuguesas, 1850-1920, Santiago de Compostela, Universidad de Santiago de Compostela, Facultad de Ciencias Económicas y Empresariales (Tesis doctoral inédita).

Estadistica Administrativa de la Contribución Industrial y de Comercio, 1859, 1879, 1900 y 1930.

Estadistica Forestal de España, 1946 a 1971.

Estadísticas del Comercio Exterior de España, 1849 a 1935.

Estadísticas de Producción de los Montes de Utilidad Pública (o de los Montes Públicos), 1901 a 1933.

FAO (1967): La madera: tendencias y perspectivas mundiales, Roma.

FitzGerald, R., y Grenier, J. (1992): Timber. A History of the Timber Trade Federation, London, Batsford.

Gallego MARTínez, D. (1998): «De los limitados efectos de la política arancelaria sobre las orientaciones productivas del sector agrario español, 1869-1914», en La política monetaria y las fluctuaciones de la economía española en el siglo XIX. Homenaje a Joan Sardá Dexeus, Barcelona, Universidad de Barcelona.

Gallego Martínez, D., y Pinilla Navarro, V. (1996): «Del librecambio matizado al proteccionismo selectivo: el comercio exterior de productos agrarios y alimentos en España entre 1849 y 1935», Revista de Historia Económica, 2, pp. 371-420.

GARCIA ESTEBAN, L. (1999): «Industrias forestales», en Ciencias y técnicas forestales. 150 años de aportaciones de los ingenieros de montes, Madrid, Fundación Conde del Valle de Salazar, pp. 487-502.

Gómez MendozA, A. (1989): Ferrocarril, industria y mercado en la modernización de España, Madrid, Espasa-Calpe.

Gómez MendozA, J. (1992): Ciencia y política de los montes españoles (1848-1936), Madrid, ICONA.

Groome, H. (1990): Historia de la política forestal en el Estado español, Madrid, Agencia del Medio Ambiente.

GRUPO de Estudios de Historia RURAL (1983): «Notas sobre la producción agraria española, 1891-1931», Revista de Historia Económica, 2, pp. 185-252. 
- (1991): Estadísticas bistóricas de la producción agraria española, 1859-1935, Madrid, Ministerio de Agricultura, Pesca y Alimentación.

- (1996a): Memoria correspondiente a la segunda entrega del proyecto de investigación "Protección versus producción de los montes públicos españoles, 1860-1979", Madrid (inédito).

- (1996b): Memoria correspondiente a la tercera entrega del proyecto de investigación "Protección versus producción de los montes públicos españoles, 1860-1979», Madrid (inédito).

- (1996c): «Política forestal y producción de los montes públicos españoles. Una visión de conjunto, 1861-1933», VIII Simposio de Historia Económica, Barcelona.

- (1999): «Diversidad dentro de un orden. Privatización, producción forestal y represión en los montes públicos españoles, 1859-1926», Historia Agraria, 18, pp. 129-177.

GuillaRD, J., y ROSSNER, F. (1974): «L'evolution des prix de bois. Tentative d'analyse sur le long terme en France», Revue Forestière Française, pp. 179.210.

GutiérRez i PoCH, M. (1994): «Tradición y cambio tecnológico: la industria papelera española, 1750-1936», en NADAL, J., y Catalán, J. (eds.), La cara oculta de la industrialización española. La modernización de los sectores no líderes (siglos XIX y XX), Madrid, Alianza, pp. 341-368.

GUTTÉRREZ POCH, M. (1996): "Control de mercado y concentración empresarial: "La Papelera Española", 1902-1935», Revista de Historia Industrial, 10, pp. 183-199.

Hasel, K. (1985): Forstgeschichte. Ein Grundiß für Studium und Praxis, Hamburg und Berlin, Paul Parei.

HOLLISTER-SHORT, G. (1994): «La otra cara de la moneda: los sistemas de transporte de madera en la Europa pre-industrial», Arbor, 586-587, pp. 133-168.

IRIARTE GoNi, J. I. (1995): Privatización, particularización y gestión de los montes públicos. Navarra, 1855-1935, Zaragoza, Universidad de Zaragoza, Facultad de Filosofía y Letras (Tesis doctoral).

IRIARTE GONNI, I. (1997): Bienes comunales y capitalismo agrario en Navarra, 1855.1935, Madrid, Ministerio de Agricultura, Pesca y Alimentación.

Kn.luAN, H. (1982): «Una innovazione selviculturale: l'introduzione della sega nell'Europa centrosettentrionale (xv-xIx secolo)», Quaderni Storici, 49, pp. 59-70.

Laarman, Jan G. (1988): «Export of Tropical Hard-Woods in the Twentieth Centurym, en J. F. RICHARDS y R. P. TUCKER (eds.), World Deforestation in the Twentieth Century, Durham and London, Duke University Press, pp. 147-163.

Latham, B. (1957): Timber. Its Development and Distribution. A Historical Survey, London, George G. Harrap.

Leban, J.-M.; Saint-André, L., y Triboulot, P. (1998): «Le bois. Un matériau de tous les ages, toujours performant», en CORVOL, A. (ed.), Les matériaux de la ville: $d u$ bois au béton?, Paris, CNRS, pp. 9-16.

Liniger-Goumaz, M. (1962): L'orange d'Espagne sur les marchés européens. Le probléme oranger espagnol, Genéve, Temps.

LLEO, A. (1929): Las realidades, las posibilidades y las necesidades forestales de España, Madrid. 
«Los madereros. Organización y trabajos de los gancheros» (1891): Revista de Montes y Plantios, p. 287.

MageE, C. B. (1997): Productivity and performance in the paper industry. Labour, capital and technology in Britain and America, 1860-1914, Cambridge, Cambridge University Press.

Mantilla, P. (1931): «Las maderadas», Montes e Industrias, pp. 113-117, 139-145 y $174-179$.

MANUel VALDÉs, C. M. (1997): Los montes españoles: estudios recientes desde las perspectivas bistórica, geográfica y forestal (1980-1996), Madrid (inédito).

Martín-Montalvo Y SANGIL, R (1985a): Escritos forestales. Quinquenio (1978-1982), Madrid, Fundación Conde del Valle de Salazar.

- (1985b): Bibliografía forestal española, Madrid, Fundación Conde del Valle de Salazar.

Ministerio de Agricultura. Dirección General de Montes, Caza y Pesca Fluvial (1963a): Estadistica de las industrias de primera transformación de la madera. Información anual. Datos de 1960, Madrid.

- (1963b): Estadística de las industrias de primera transformación de la madera. Información anual. Datos de 1961, Madrid.

- (1964): Estadística de las industrias de primera transformación de la madera. Información anual. Datos de 1962, Madrid.

Mrtchell, B. R. (1992): Intemational Historical Statistics. Europe 1750-1988, 3. a ed., New York, Stockton Press.

NADAL, J. (1990): «El desarrollo de la economía valenciana en la segunda mitad del siglo XIX: cuna vía exclusivamente agraria?», en J. NADAL y A. CARRERAS (dirs.), Pautas regionales de la industrialización española (siglos XIX y XX), Barcelona, Ariel, pp. 296-314.

NájerA, F. (1934): La técnica de la madera en la construcción moderna, Madrid.

NAREDO, J. M. (1987): La economía en evolución. Historia y perspectivas de las categorias básicas del pensamiento económico, Madrid, Siglo XXI.

Neira, M., y Martínez MATA, F. (1973): Terminologia forestal española, Madrid, Ministerio de Agricultura.

NicolaU, R. (1989): «La población», en A. CARreras (coord.), Estadísticas bistóricas de España, siglos XIX-XX, Madrid, Fundación Banco Exterior, pp. 49-90.

Noél, M., y Bocquet, A. (1987): Les bommes et le bois. Histoire et technologie du bois de la prébistoire à nos jours, Paris, Hachette.

NorTh, M. (1996): «Trade and Production of Timber and Timber By-Products in the Baltic Region, 1575-1775», en S. CAvaCiocCHI (ed.), L'uomo e la foresta, secc. XIII-XVII, Firenze, Le Monnier, pp. 883-894.

«L'organization internationale du marché du bois» (1936): Revue des Eaux et Forêts, pp. $539-545$.

Paris Eguilaz, H. (1943): El movimiento de precios en España. Su importancia para una politica de intervención, Madrid, CSIC.

Perlin, J. (1999): Historia de los bosques. El significado de la madera en el desarrollo de la civilización, Madrid, Gaia Proyecto 2050.

Perrot, Ch. (1957a): «Prix de bois», Revue Forestière Française, pp. 397-402.

- (1957b): «Prix de bois et valeurs mobilières», Revue Forestière Française, pp. $761-767$. 
Pinilla Navarro, V. (1995a): «Cambio agrario y comercio exterior en la España contemporánea», Agricultura y Sociedad, 75, pp. 153-180.

- (1995b): Entre la inercia y el cambio. El sector agrario aragonés, 1850-1935, Madrid, Ministerio de Agricultura, Pesca y Alimentación.

PitTer, C. (1932): «Economía y política forestal de los soviets y sus efectos sobre los demás países productores de madera», Montes e Industrias, pp. 559-563.

Prados DE la Escosura, L. (1982): Comercio exterior y crecimiento económico en España, 1850-1935, Madrid, Banco de España.

Rico Boquete, E. (1994): A riqueza forestal de Galicia no século xx. Producción e explotación, Santiago de Compostela, Universidad de Santiago de Compostela, Facultad de Geografia e Historia (Tesis doctoral inédita).

- (1999): Montes e industria forestal en la provincia de Pontevedra (1900-1975). Antecedentes y desarrollo de la Empresa Nacional de Celulosas, S. A. Del aserrio mecánico a la creación de celulosas de Pontevedra, Coruña, Tórculo.

ROBERT ROBERT, A. (dir.) (1957): La producción forestal y el crecimiento económico, Madrid, Instituto de Cultura Hispánica.

Robertson, F. C. (ed.) (s. a.): Terminología de la ciencia forestal, tecnología práctica $y$ productos. Versión española (s. 1.).

RUBNER, H. (1967): Forstgeschichte im Zeitalter der industriellen Revolution, Berlin, Duncker\&Humblot.

RuBNER, K. (1920): Die Bewegung der Holzpreise in Deutschland von Begin des Weltbolzwandels bis zum Weltkrieg, Neudamm.

SABIo AlCutÉn, A. (1997): Los montes públicos en Huesca (1859-1930). El bosque no se improvisa, Huesca, Diputación de Huesca.

SALA, P. (1998): Sobre la compatibilitat entre bosc productor $i$ bosc protector (La Catalunya forestal bumeda entre la societat agrària $i$ la societat industrial, 1850-1930), Barcelona, Universidad Autónoma de Barcelona, Facultad de Ciencias Económicas y Empresariales (Tesis doctoral inédita).

Sánchez Martínez, J. D., y Gallego Simón, V. J. (1993): La política de repoblación forestal en España, siglos XIX y XX: planteamientos, actuaciones y resultados. Estado de la cuestión y recopilación bibliográfica, Madrid, Ministerio de Agricultura, Pesca y Alimentación.

«Sección mercantil» (1902): Revista de Montes, pp. 429-432.

SEITZ, F. (1998): «Le bois, le métal, concurrence?», en A. CoRvol (ed.), Les matériaux de la ville: du bois au béton?, Paris, CNRS, pp. 45-48.

Soederlund, E. F. (ed.) (1952): Swedish Timber Exports, 1850-1952: A History of the Swedish Timber Trade, Estocolmo.

Soulekes, G. (1997a): «L'évolution des prix des bois sur pied (1955-1995). Première Partie: Les principaux produits», Revue Forestière Française, pp. 451-468.

- (1997b): «L'évolution des prix des bois sur pied (1955-1995). Deuxième Partie: Pour un indice global», Revue Forestière Française, pp. 579-589.

Steer, H. B. (ed.) (1948): Lumber Production in the United States, 1799-1946, Washington DC, Department of Agriculture.

Torres, M. de, y Paris Eguilaz, H. (1950): La naranja en la economia española, Madrid.

Tree CD 1939-April 1995 (1995): Silver Platter International N. V. (CD-ROM). 
Triboulot, P., y Leban, J.-M. (1998): «Le bois. Nouvelles technologies et nouveaux matériaux», en A. Corvol (ed.), Les matériaux de la ville: du bois au béton?, Paris, CNRS, pp. 18-22.

Turner, R. D. (1990): Logging by Rail: the British Columbia Story, Victoria, Sono Nis Press.

Vignote Peña, S., y Jiménez Peris, F. J. (1996): Tecnología de la madera, Madrid, Ministerio de Agricultura, Pesca y Alimentación y Mundi-Prensa.

Williams, T. I. (1987): Historia de la tecnologia, vol. 4, Desde 1900 basta 1950 (I), Madrid, Siglo XXI.

- (1990): Historia de la tecnologia, vol. 5, Desde 1900 basta 1950 (II), Madrid, Siglo XXI.

WoronofF, D. (1996): «Le bois, combustible de l'industrie: remarques sur l'exemple français (XVI-XVIII)», en S. CAVACIOCCHI (ed.), L'uomo e la foresta, secc. XIII-XVIII, Firenze, Le Monnier, pp. 859-878.

XiméneZ de EMBÚn y OSEÑALDE, J. (1932): «La repoblación forestal en sus relaciones con la producción e industrias de la madera», Montes e Industrias, pp. 355-358.

Zambrana Pineda, J. F. (1998): La acción del Estado en el sector forestal: producción y gestión de los montes españoles, 1946-1979, con especial referencia al espacio forestal andaluz, Málaga (inédito).

Zapata BlanCO, S. (1998): Historia económica de la madera en España, desde mediados del siglo XIX a 1936. Un primer esbozo, Badajoz (inédito). 